\title{
An Improved Soil Moisture Retrieval Algorithm for ERS and METOP Scatterometer Observations
}

\author{
Vahid Naeimi, Klaus Scipal, Member, IEEE, Zoltan Bartalis, \\ Stefan Hasenauer, and Wolfgang Wagner, Senior Member, IEEE
}

\begin{abstract}
The scatterometers onboard the European Remote Sensing satellites (ERS-1 \& ERS-2) and the METeorological OPerational satellite (METOP) have been shown to be useful for surface soil moisture retrieval using the so-called TU-Wien change detection method. This paper presents an improved soil moisture retrieval algorithm based on the existing TU-Wien method but with new parameterization as well as a series of modifications. The new algorithm, WAter Retrieval Package 5 (WARP5), copes with some limitations identified in the earlier method WARP4 and provides the possibility of migrating soil moisture retrieval from ERS-SCAT to METOP-ASCAT data. The WARP5 algorithm results in a more robust and spatially uniform soil moisture product, thanks to its new processing elements, including a method for the correction of azimuthal anisotropy of backscatter, a comprehensive noise model, and new techniques for calculation of the model parameters. Cross-comparisons of WARP4 and WARP5 data sets with the Oklahoma Mesonet in situ observations and also with European Centre of Medium Range Weather Forcast (ECMWF) ReAnalysis (ERA-Interim) global modeled data show that the new algorithm has a better performance and effectively corrects retrieval errors in certain areas.
\end{abstract}

Index Terms-European Remote Sensing satellite (ERS), METeorological OPerational satellite (METOP), scatterometer, soil moisture.

\section{INTRODUCTION}

$\mathbf{I}$ N OCTOBER 2006, the European Organization for the Exploitation of Meteorological Satellites (EUMETSAT) launched METOP-A, the first of three satellites within EUMETSAT's Polar System (EPS) [1]. One of the instruments onboard the satellite is the Advanced Scatterometer (ASCAT), the successor instrument of the European Remote Sensing satellites (ERS)-1/2 scatterometers (SCATs) [2]. Scatterometers have been designed to measure wind speed and direction at the sea surface using radar technology. Since the launch of ERS-1 in 1991, wind retrieval from scatterometers has become a

Manuscript received June 11, 2008; revised October 21, 2008. This work was supported in part by the European Organization for the Exploitation of Meteorological Satellites under Contract EUM/CO/05/1421/HGB and in part by the Austrian Science Fund under Project L148-N10.

V. Naeimi, Z. Bartalis, S. Hasenauer, and W. Wagner are with the Institute of Photogrammetry and Remote Sensing, Vienna University of Technology, 1040 Vienna, Austria (e-mail: vn@ipf.tuwien.ac.at; zb@ipf.tuwien.ac.at; sh@ipf.tuwien.ac.at; ww@ipf.tuwien.ac.at).

K. Scipal is with the European Centre for Medium-Range Weather Forecasts, RG2 9AX Reading, U.K. (e-mail: Klaus.Scipal@ecmwf.int; ks@ipf.tuwien.ac.at).

Color versions of one or more of the figures in this paper are available online at http://ieeexplore.ieee.org.

Digital Object Identifier 10.1109/TGRS.2008.2011617 routine application, and the derived information is used operationally for various purposes such as numerical weather prediction [3]. Aside from its intended task as an ocean monitoring tool, there is increasing evidence that the ERS and METOP scatterometers also allow for the measurement of soil moisture over land. From a physical point of view, scatterometers offer a relatively direct opportunity to measure soil moisture because of the high sensitivity of microwaves to the water content in the soil surface layer. This is specifically the case in the lowfrequency domain $(1-10 \mathrm{GHz})$ in which the scatterometers operate. The major challenge of retrieving soil moisture is the presence of additional factors influencing the signal, such as surface roughness and vegetation.

To retrieve vegetation and soil properties from scatterometer observations, most approaches use inversion methods based on physical approximations of the scattering process [4]-[9]. They typically use simple bare soil backscattering models like the one proposed by Oh et al. [10] or Fung et al. [11] and vegetation models similar in form to the so-called Cloud Model [12] or site-specific vegetation growth models like the one used by Mougin et al. [13] for Sahelian regions. Major problems of these retrieval concepts appear to be their physical validity at large scales and their parameterization. For example, Davidson et al. [14] demonstrated the limited range of validity of currently available bare soil backscatter models. Grippa and Woodhouse [15] noted the difficulty of modeling backscatter from heterogeneous land cover and pointed out the need to further investigate scaling processes.

Wagner et al. [16] presented a possible solution to these problems by utilizing the unique sensor design of the ERS/METOP scatterometers and a change detection method which will further be referred to as the TU-Wien model. Several studies showed that the change detection technique can overcome some of the problems of physical-based inversion models if sufficient long-term data are available as it directly accounts for the scattering process of rough and heterogeneous land surfaces. The potential of using such methods has been demonstrated for both active and passive microwave data [17]-[22].

In the TU-Wien model, a reference backscatter value representing backscatter from the vegetated land surface under dry soil conditions is subtracted from the actual backscatter measurement to account for roughness and heterogeneous land cover. To account for the effects of plant growth and decay, the vegetation-sensitive signature of the multi-incidence angle observations is exploited. Soil moisture is finally retrieved by relating the actual backscatter measurement to dry/wet references, resulting in a relative measure of soil moisture [16].

(C) 2009 IEEE. Personal use of this material is permitted. Permission from IEEE must be obtained for all other uses, in any current or future media, including reprinting/republishing this material for advertising or promotional purposes, creating new collective works, for resale or redistribution to servers or lists, or reuse of any copyrighted component of this work in other works. 
Scipal [23] used the method to derive the first remotely sensed global soil moisture data set. During recent years, this data set has been evaluated in several validation studies [24]-[27]. The data were also used successfully in hydrologic [28], [29] and climate studies [30] and in first assimilation experiments [31], [32]. The positive feedback of these studies motivated the implementation of an operational near-real-time METOP ASCAT processor at EUMETSAT's central processing facility [33]. Initial soil moisture retrieval tests, based on ASCAT observations, indicate that the advanced sensor design and calibration will deliver more accurate soil moisture data with an almost daily temporal sampling at a spatial resolution of approximately $25 \mathrm{~km}$ [34]. Hence, the METOP system has the potential to provide an uninterrupted flow of soil moisture information until at least 2020 and, as such, offer an attractive complement to dedicated soil moisture missions planned for launch in the near future, like the European Space Agency's Soil Moisture and Ocean Salinity Mission (SMOS) and NASA's Soil Moisture Active Passive mission (SMAP). The near-realtime operational system capabilities and the heritage of the ERS-1/2 missions will make it a valuable monitoring tool for various applications.

The implementation of the TU-Wien method for operational soil moisture processing however requires a careful revisit of the existing model. The original method as proposed by Wagner et al. [16] was developed and tested over Mali, Spain, Ukraine, and Canada. Although Wagner et al. [24] found that the transfer of the method to a global scale lead to satisfactory results, some shortcomings of the algorithm have been identified. These are as follows: 1) the azimuthal look direction of the sensor is not explicitly incorporated in the retrieval; 2) the backscatter normalization parameters of the model, which correspond to yearly vegetation change, are determined on a monthly basis, neglecting higher frequency variations; 3 ) the estimation of the dry/wet reference values lead to spatially inconsistent results, particularly in the presence of high noise; and 4) a persistent error model was lacking.

In this paper, we therefore propose and evaluate an improved retrieval scheme which will address these problems by reprocessing 16 years of SCAT data. For a better understanding of the retrieval concept, a short description of the ERS/METOP scatterometer data is given in Section II, and a brief review of the earlier version of the soil moisture retrieval algorithm [WAter Retrieval Package 4 (WARP4)] is made in Section III. In Section IV, we introduce the improved retrieval algorithm (WARP5). Finally, we compare WARP4 and WARP5 soil moisture data with the in situ soil moisture observations from the Oklahoma Mesonet network. We also use a global soil moisture data set from the European Centre for Medium-Range Weather Forecasts (ECMWF)'s reanalysis project called ERA-Interim, a numerical weather prediction model, to evaluate the impact of the retrieval modifications on soil moisture estimates.

\section{SCATTEROMETER DATA}

Scatterometers are microwave sensors designed to measure the normalized radar cross section $\sigma^{0}$ with high radiometric accuracy over a set of different incident angles while scanning

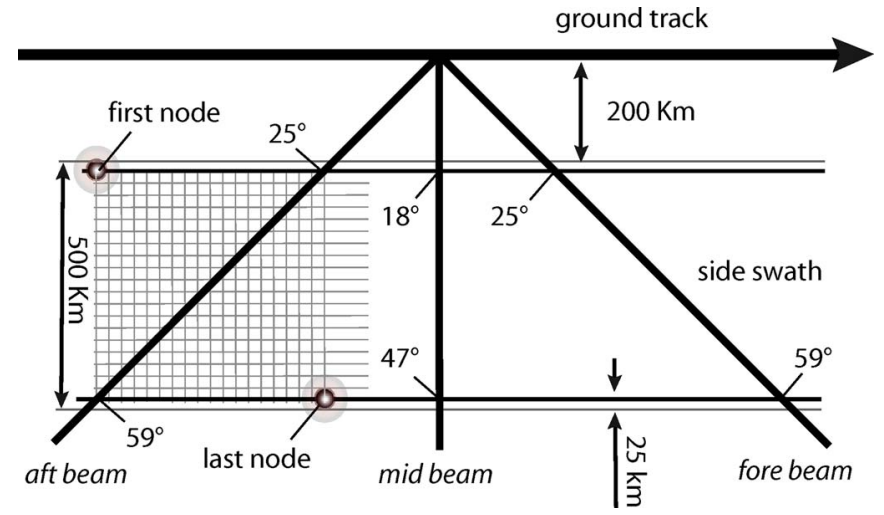

Fig. 1. SCAT viewing geometry.

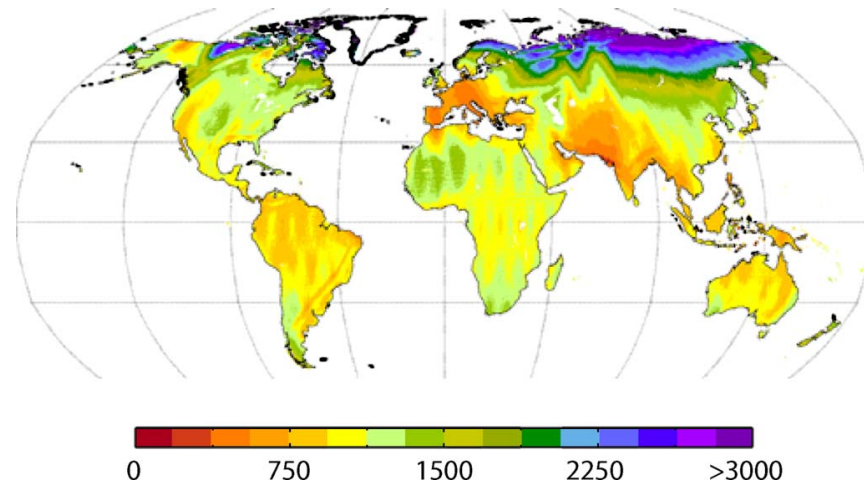

Fig. 2. Number of the resampled SCAT measurements from August 1991 to May 2007.

the surface of the Earth from an aircraft or a satellite. They have the advantage of providing day and nighttime measurements unaffected by cloud cover. Spaceborne Scatterometers are used to measure surface properties with relatively coarse spatial resolutions but on a more frequent basis.

\section{A. SCAT Onboard ERS-1 and ERS-2}

The SCAT onboard ERS is part of the active microwave instrument consisting of a synthetic aperture radar and a fanbeam scatterometer operating in C-band $(5.6 \mathrm{GHz})$ at $\mathrm{VV}$ polarization. The three SCAT antennas generate radar beams looking $45^{\circ}$ forward, $90^{\circ}$ sideways, and $135^{\circ}$ backwards with respect to the satellite's flight direction, at incidence angles ranging from $18^{\circ}$ to $59^{\circ}$. The three antenna beams continuously illuminate a 500-km-wide swath, each measuring the radar backscatter for overlapping 50-km-wide cells. The result is three independent backscatter measurements at the nodes of a $25-\mathrm{km}$ orbit grid (Fig. 1), taken at different viewing angles and separated by a short time delay [35].

ERS-1 regularly acquired data between August 1991 and May 1996. ERS-2 operated nominally between March 1996 and January 2001, when due to a failure of a gyroscope, all ERS-2 instruments were temporarily switched off. Since May 2004, ERS-2 again acquires data; however, reception of data is limited to selected regions (i.e., North America, Europe, Northwest Africa, China, and Australia) as ERS-2 lost its onboard data storage capability in June 2003. Fig. 2 shows the availability of 
the SCAT measurements on a global scale from August 1991 to May 2007. In April 2007, the ERS-2 spacecraft reached its twelfth year in orbit. Apart from some minor problems, all platform subsystems and payload instruments are working satisfactorily and are providing high-quality data. Recently, the ERS-2 mission was approved to be continued for three more years until 2011.

\section{B. ASCAT Onboard METOP}

The ASCAT, like its predecessor SCAT, uses a fan-beam antenna technology. Contrary to SCAT, it uses two sets of three antennas. For ASCAT, the incidence angle range has been extended to $25^{\circ}-65^{\circ}$. ASCAT covers two $550-\mathrm{km}$ swaths to the left and right of the satellite ground track separated by approximately $360 \mathrm{~km}$ from the satellite ground track. This results in a double daily spatial coverage with respect to its predecessor SCAT. Apart from the optimized viewing geometry, ASCAT also features a number of technical improvements. The improved instrument design and radiometric performance result in higher stability and reliability of $\sigma^{0}$ measurements. In addition to the $50-\mathrm{km}$ backscatter product foreseen for operational wind monitoring, EUMETSAT delivers an equivalent product at a resolution of $25 \mathrm{~km} \mathrm{[2].}$

\section{WARP4 Algorithm RevieW}

\section{A. Analysis Grid}

In order to apply a change detection method for retrieving relative soil moisture, $\sigma^{0}$ measurements are required as time series. In WARP4, all ERS-1/2 measurements were collocated from the satellite orbit grid into a Discrete Global Grid (DGG), a sinusoidal global grid generated by an adapted partitioning of the globe with an approximately $25-\mathrm{km}$ grid spacing [23]. In this way, each grid point is associated with a series of $\sigma^{0}$ spatially resampled using a fixed sampling area. To provide enough measurements for the interpolation procedure in each satellite pass, the radius of the sampling area was set to $36 \mathrm{~km}$, considering the $25-\mathrm{km}$ SCAT orbit grid. This area includes the adjacent grid points of each DGG point also in diagonal direction, located at about $35.4 \mathrm{~km}$ at most. The spatial interpolation of the data in each grid point is performed after the incidence angle normalization of $\sigma^{0}$ measurements, by using the Hamming window function

$$
H(r)=0.54+0.46 \cos \left(\frac{\pi r}{R_{H}}\right)
$$

where $r$ is the distance to the center of the window and $R_{H}$ is the window radius. The Hamming window is a function frequently used in radar remote sensing for interpolation of irregularly distributed data [36].

\section{B. Viewing Geometry Normalization}

The $\sigma^{0}$ measurements collocated to each DGG point are taken at different incidence angles. As the intensity of backscatter signal strongly depends on the incidence angle, the $\sigma^{0}$ measurements cannot be compared directly and need to be normalized to a reference incidence angle. Therefore, all $\sigma^{0}$ measurements are extrapolated to a reference angle of $40^{\circ}$ using a second-order polynomial according to

$$
\sigma^{0}(40, t)=\sigma^{0}(\theta, t)-\sigma^{\prime}(40, t)(\theta-40)-\frac{1}{2} \sigma^{\prime \prime}(40, t)(\theta-40)^{2}
$$

The reference angle is set to $40^{\circ}$ in order to minimize extrapolation errors [37]. The parameters of this model, the slope $\sigma^{\prime}$, and the curvature $\sigma^{\prime \prime}$ are determined from simultaneous multiincidence angle observations

$$
\sigma^{\prime}\left(\frac{\theta_{m}-\theta_{a / f}}{2}\right)=\frac{\sigma_{m}^{0}\left(\theta_{m}\right)-\sigma_{a / f}^{0}\left(\theta_{a / f}\right)}{\theta_{m}-\theta_{a / f}}
$$

where the index $m$ stands for the midbeam antenna and the indexes $a$ or $f$ for either the aft- or forebeam antennas. Having a large set of samples evenly distributed over the entire incidence angle range, $\sigma^{\prime}(40)$ and $\sigma^{\prime \prime}(40)$ can be derived by fitting a linear model of the form

$$
\sigma^{\prime}(\theta)=\sigma^{\prime}(40)+\sigma^{\prime \prime}(40)(\theta-40) .
$$

It has to be mentioned that each $\sigma^{\prime}(40)$ triplet only allows one to calculate an approximation, which is only valid near the respective incidence angle and which is disturbed by measurement noise. To account for noise effects and to ensure that the parameters of (2) are estimated from measurements evenly distributed over the entire incidence angle range, the parameters are calculated for a large number of $\sigma^{0}(\theta)$ triplets. The exact shape of the polynomial expressed in (2) depends on the land surface properties, i.e., it is sensitive to the vegetation and surface structure. Smooth surfaces with no vegetation result in a steep decline of $\sigma^{0}$ with respect to $\theta$ and, therefore, low negative $\sigma^{\prime}$ values. Vegetation and rough surfaces generally result in higher $\sigma^{\prime}$ values. This is important to note, as the normalization of $\sigma^{0}$ has to take vegetation growth/decay effects into account. Therefore, the parameters are estimated for each month of the year. Consequently, 12 values of $\sigma^{\prime}(40)$ and $\sigma^{\prime \prime}(40)$ are obtained. Interpolation between these monthly values is done by using empirical trigonometric functions according to

$$
\sigma^{\prime}(40, t)=C^{\prime}+D^{\prime} \psi(t)
$$

where $\psi(t)$ is one of the 68 predefined periodic functions describing the dynamic evolution of $\sigma^{\prime}(40)$. As an example, over the Iberian Peninsula, a simple sine model is used for the determination of the slope function [38]

$$
\psi(t)=\frac{1}{2} \sin \left(\frac{2 \pi}{12}(t-3)\right) .
$$

Using prescribed empirical functions instead of a simple interpolation has the advantage of a controlled interpolation, leading to robust estimates. Fig. 3 shows monthly slope values at $40^{\circ}$ and the respective periodic function for a grid point located in Mali, Africa $\left(15^{\circ} 7^{\prime} 30^{\prime \prime} \mathrm{N}, 8^{\circ} 40^{\prime} 34^{\prime \prime} \mathrm{W}\right)$. The empirical model of (5) fits well to the monthly slope values. Small deviations are visible only during January and February. The 


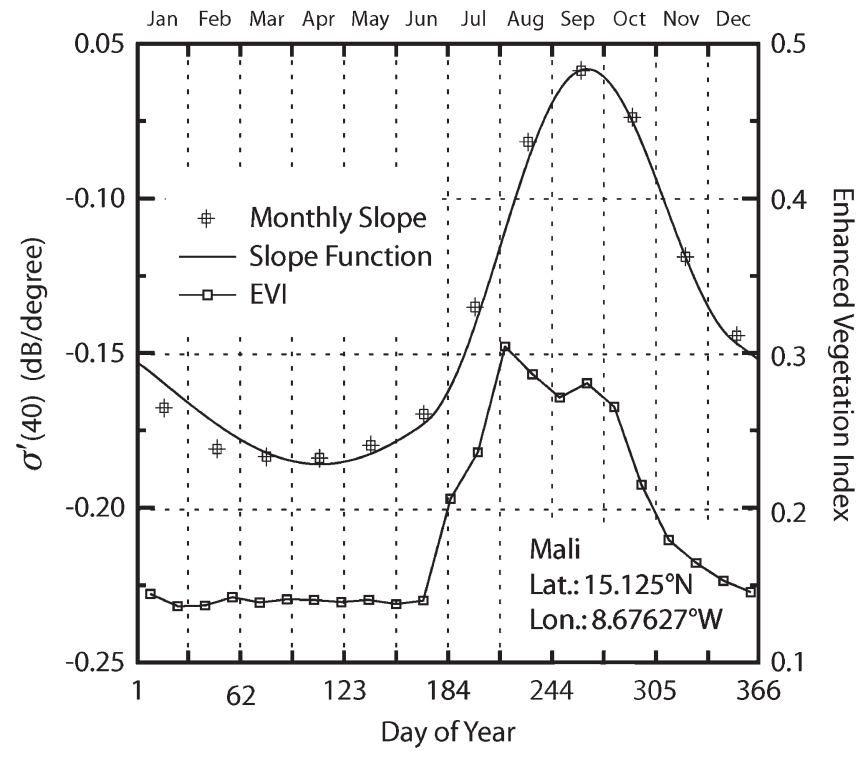

Fig. 3. WARP4 monthly slope values at $40^{\circ}$ and respective slope function $\sigma^{\prime}(40, \tau)$ comparing with 16-day MODIS EVI data averaged over three years (2000-2002).

slope function $\sigma^{\prime}(40, t)$ represents variations of vegetation canopies within a year. The $\sigma^{\prime}$ values are satisfactorily correlated with the vegetation index data, although the vegetation index corresponds to the greenness and not the vegetation biomass, which is more relevant for $\mathrm{C}$-band backscatter. The vegetation index data in Fig. 3 have been derived from a 16-day Moderate Resolution Imaging Spectroradiometer (MODIS) enhanced vegetation index (EVI) product [39]. EVI values are averaged over three years (2000-2002) to obtain an estimation of the yearly vegetation variation.

\section{Soil Moisture Retrieval}

The dominant mechanisms contributing to $\sigma^{0}(40)$ are volume scattering effects in the vegetation canopy and surface scattering from the underlying soil surface [40]. In simple radiative transfer models like the Cloud Model [12], the effect of vegetation is largely controlled by the optical depth which weights the relative contribution of surface and volume scattering. Although the TU-Wien model uses a different parameterization, it is similar in functionality to these models. When vegetation grows, the optical depth increases, and the volume scattering term becomes more important. This does not necessarily mean that backscatter increases. In situations where the reduced contribution from the underlying ground is more important than the enhanced volume scattering, $\sigma^{0}$ decreases. For low incidence angles, the effect of vegetation is mainly the attenuation of the signal returned by underlying soil [41]. In other words, backscattering from bare soil is, in general, stronger than vegetated soil in near range. Because of the rapid drop-off of the bare soil backscattering, the situation may be reversed at high incidence angles. Therefore, at some incidence angle, $\sigma^{0}(\theta)$ curves of a developing and a full-grown vegetation canopy should cross over [42]. In the TU-Wien model, it is assumed that the effect of vegetation is minimal at the so-called "crossover" angles $\theta_{\text {dry }}$ and $\theta_{\text {wet }}$, which differ for dry and wet soil conditions. If such crossover angle exists, then for dry conditions, it should be found at lower incidence angles than for wet conditions [37]. By considering these crossover angles and using (2) and (5) after separating the time-dependent and constant terms, the lowest level of the backscattering $\sigma_{\text {dry }}^{0}$ at $40^{\circ}$ is given by

$$
\sigma_{\mathrm{dry}}^{0}(40, t)=C_{\mathrm{dry}}^{0}-D^{\prime} \psi(t)\left(\theta_{\mathrm{dry}}-40\right)
$$

where $C_{\mathrm{dry}}^{0}$ is the minimum value of $\sigma_{\mathrm{dry}}^{0}$ at the dry crossover angle $\theta_{\text {dry }}$, which is empirically set to $25^{\circ}$.

The same reasoning can be applied for wet soil conditions to obtain the highest level of backscatter

$$
\sigma_{\text {wet }}^{0}(40, t)=C_{\text {wet }}^{0}-D^{\prime} \psi(t)\left(\theta_{\text {wet }}-40\right)
$$

where $C_{\text {wet }}^{0}$ is the maximum value of $\sigma_{\text {wet }}^{0}$ at the wet crossover angle $\theta_{\text {wet }}$ empirically set to $40^{\circ}$.

The dry and wet references derived in (7) and (8) are finally used to determine variations in the soil moisture content. Assuming a linear relationship between $\sigma^{0}(40)$ and the surface soil moisture content [43], the relative soil moisture content in the surface layer is calculated as

$$
\Theta_{s}(t)=\frac{\sigma^{0}(40, t)-\sigma_{\mathrm{dry}}^{0}(40, t)}{\sigma_{\text {wet }}^{0}(40, t)-\sigma_{\mathrm{dry}}^{0}(40, t)} .
$$

$\Theta_{s}(t)$ is a relative measure of the water content in the surface layer ranging between zero and one (0\%-100\%). Assuming that $\sigma_{\text {dry }}^{0}$ represents a completely dry soil surface and $\sigma_{\text {wet }}^{0}$ a saturated one, $\Theta_{s}(t)$ is equal to the degree of saturation, i.e., the soil moisture content expressed in percent of porosity [44]. The reference values $\sigma_{\text {dry }}^{0}$ and $\sigma_{\text {wet }}^{0}$ are estimated from the lowest and highest $\sigma^{0}(40)$ extremes acquired during the period of August 1991-May 2007. By using such long-term data, the reference values will likely represent the respective soil conditions even in temporal sparsely sampled areas. In extreme climates such as deserts, where saturation is never observed, an empirical bias-correction factor is applied to $\sigma_{\text {wet }}^{0}$ in order to obtain spatially consistent soil moisture estimates.

\section{TU-Wien Algorithm UPDATES IN WARP5}

WARP5 is the latest revision of the TU-Wien algorithm. The motivation on setting up WARP5 was implementing a more robust processing algorithm and extending the model to cover some model deficiencies in WARP4. In this section, we introduce the new aspects in WARP5 and highlight major differences between the new algorithm and WARP4.

\section{A. Resampling Scatterometer Data to a New DGG}

The grid used in WARP4 was based on simplified assumptions to disburden data resampling. These are 1) a spherical model of the Earth; 2) a geocentric coordinate system; and 3) no full compliance with the requirement for uniform grid spacing. Using a simplified model of the Earth, not compliant with the model used during the data generation process, leads to collocation and coordinate transformation errors. To minimize these errors, a new grid is implemented in WARP5. Apart from 
a new physical definition of the analysis grid, the grid point spacing is reduced by a factor of two. This makes it possible to 1) include directly the ASCAT fine resolution $(25 \mathrm{~km})$ product in the analysis and 2) build up a consistent soil moisture data set including both SCAT and ASCAT data. The new grid is based upon the GEM6 ellipsoid, which is also used during the ground range projection of SCAT and ASCAT data [45], and generated by an adapted partitioning of the globe with an about $12.5-\mathrm{km}$ equal grid spacing [46].

In addition to the new grid, the way the observations are collocated has been modified. In WARP4, the Hamming function defined in (1) is used once the $\sigma^{0}(40)$ is derived. In WARP5, the Hamming weighting function is applied at the very first step of the processing for the backscatter coefficients $\sigma^{0}$ as well as for the azimuthal and incidence angles $\varphi$ and $\theta$, respectively, for each beam. This results in a more accurate calculation of the model parameters.

\section{B. Azimuthal Correction}

In the previous section, the need for normalizing backscatter signal with respect to the viewing geometry has been discussed, and the method used in WARP4 to correct incidence angle effects was presented. The intensity of the backscattered signal, however, does not only depend on the incidence angle but also on the azimuthal look direction. The WARP4 implementation of the TU-Wien model does not explicitly incorporate these effects, as they are generally weak. In regions characterized by surface patterns and microreliefs (e.g., sand desert) with a distinct azimuthal orientation, this simplification results in an artificial modulation of the signal [47]. In WARP5, such effects are partly corrected using the multilooking capabilities of the sensor.

Two of the three side-looking antennas of SCAT look at the surface with the same incidence angle but from two different azimuth angles (the same is valid for ASCAT having two antenna triplets on each side of the satellite track). The difference between the fore- and aftbeam backscattering coefficients $\left(\sigma_{\text {fore }}^{0}-\sigma_{\mathrm{aft}}^{0}\right)$ is therefore a measure of azimuthal dependence plus the noise level of the individual $\sigma^{0}$ measurements [48]. To account for the azimuthal effects, a normalization technique is used. In this method, a correction factor is applied to the backscatter measurements of each beam separately. To calculate the correction factors, a second-order polynomial is applied to model the $\sigma^{0}$ variations with respect to the incidence angle $\theta$ for three possible azimuth angles (i.e., for each beam and for ascending and descending passes separately). The difference between these polynomials and the polynomial derived for the entire data set is used as a correction bias.

A measure to quantify the effect of this correction on the retrieval is the estimated standard deviation (ESD) of $\sigma^{0}$ calculated as

$$
\operatorname{ESD}\left(\sigma^{0}\right)=\frac{\operatorname{StDev}\left(\sigma_{\text {fore }}^{0}-\sigma_{\text {aft }}^{0}\right)}{\sqrt{2}}
$$

Fig. 4 shows two histograms of global ESD values before and after the measurements have been corrected for azimuthal

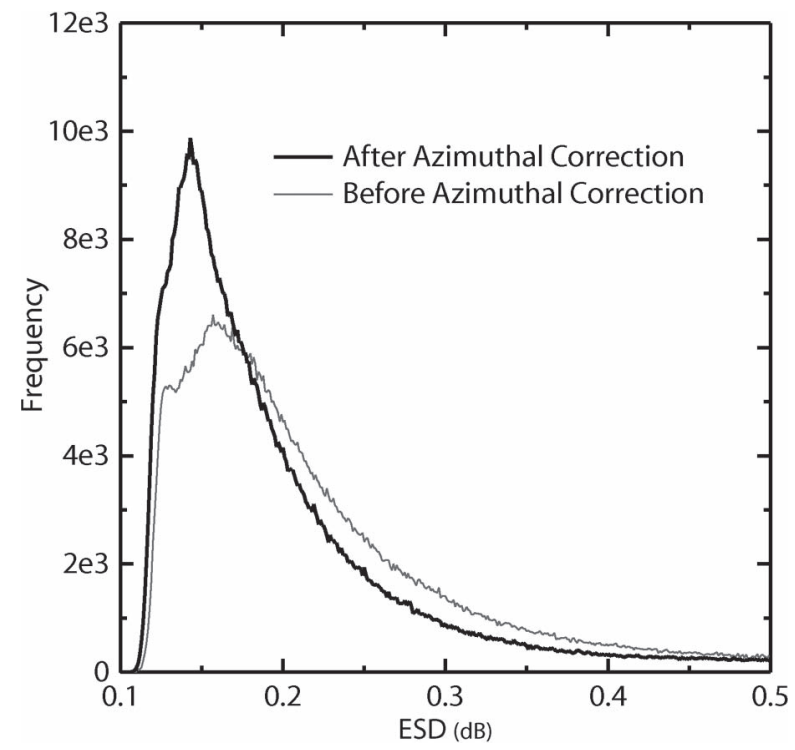

Fig. 4. Distribution of the ESD of backscatter in WARP4 and WARP5 in global scale before and after azimuthal anisotropy correction.

viewing effects. According to the observations over rainforest, the relative radiometric stability of SCAT is estimated as $0.13 \mathrm{~dB}$ [42], [49]. The histogram in Fig. 4 shows a clear peak close to this level. The skewed shape of the distribution toward higher values is an indication of azimuthal effects and proves the need for a correction. The fact that the majority of values center around a level of $0.15 \mathrm{~dB}$ indicates that, over most parts of the Earth, land surface azimuthal effects have a negligible impact on the measurements. After correcting the measurements for azimuthal effects, a clearly noticeable shift toward lower values is visible in the histogram.

\section{Slope and Curvature Calculation}

In the previous section, it was argued that the main factor influencing the $\sigma^{0}$ versus $\theta$ relationship is vegetation and its phenological cycle. The rate of vegetation change refers to the vegetation growth length, which varies depending on mean annual temperature, precipitation, incoming solar radiation, as well as land cover type. The method currently in use to parameterize this effect is to fit a first-order polynomial to the local slope values calculated in (3) to estimate the parameters in (4), $\sigma^{\prime}(40)$ and $\sigma^{\prime \prime}(40)$ on a time-window basis. In the older formulation, the time window is set to one month. The reason for using monthly estimates was robustness with respect to noise, but a one-month sampling window filters high-frequency variations. Furthermore, in some cases, the applied empirical function $\psi(t)$ used in (5) cannot satisfactorily describe natural variations. This problem is particularly evident at the beginning of the vegetation development or vegetation dormancy onset. To quantify the impact of the time-window length in the estimation of $\sigma^{\prime}$ in (4), we calculate $\sigma^{\prime}$ for different values of $\tau$, the period for which $\sigma^{0}$ measurements are sampled for the slope calculation

$$
\sigma^{\prime}(\theta, \tau)=\sigma^{\prime}(40, \tau)+\sigma^{\prime \prime}(40, \tau)(\theta-40) .
$$




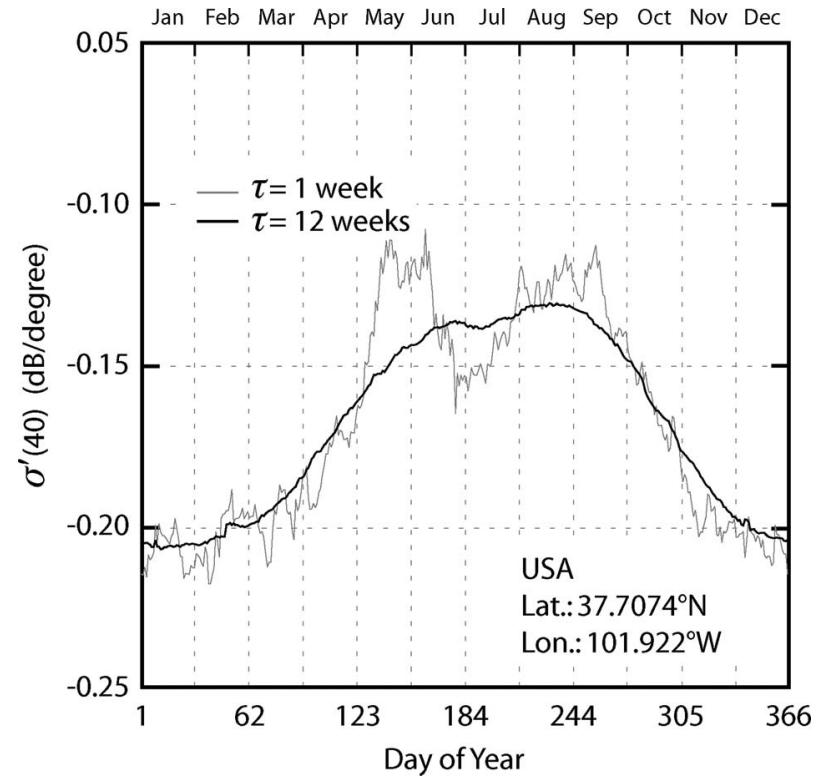

Fig. 5. Daily slope parameter calculated for two different time-window lengths.

Smaller $\tau$ values guarantee accounting for any temporal variations of the slope parameter. It should, however, be noted that there is a lower limit in defining $\tau$, as the noise of the slope function $\sigma^{\prime}(40, t)$ increases with a decreasing number of measurements. Fig. 5 shows the result of setting the $\tau$ value to 1 and 12 weeks, respectively. By setting $\tau$ to one week, seasonal variations of the slope are well captured. However, the resulting estimate appears very noisy. Setting $\tau$ to 12 weeks results in a smooth estimate which reflects the general vegetation cycle but this eliminates a considerable part of the variation. To estimate the magnitude of the error caused by different settings of $\tau$, we calculate the relative noise of the slope by comparing it with the averaged series of $\sigma^{\prime}(40, \tau)$

$$
\bar{\varepsilon}=\sqrt{\frac{1}{N} \sum_{i=1}^{N}\left(\sigma_{i}^{\prime}(40, \tau)-\bar{\sigma}_{i}^{\prime}(40, \tau)\right)^{2}}
$$

where $\sigma^{\prime}(40, \tau)$ is the slope at $40^{\circ}$ and $\bar{\sigma}^{\prime}(40, \tau)$ is the smoothed series of $\sigma^{\prime}(40, \tau)$, generated by using a moving average window of one month. Fig. 6 shows how the relative noise of slope function decreases by considering larger $\tau$ values. Setting $\tau>10$ results in more stable estimates of the slope.

To overcome this caveat and have a tradeoff between a noisy but sensitive and a stable but less responsive $\sigma^{\prime}$, a method similar to Monte Carlo (MC) simulation [50] is employed for the slope parameter estimation. It is, in general, assumed that, for a $50-\mathrm{km}$ resolution, the vegetation change is not globally remarkable in less than a two-week period, and the seasonal vegetation change does not take longer than 12 weeks. In this way, $\sigma^{\prime}(40)$ is determined as the mean of simulated $\sigma^{\prime}(40, \tau)$ values given a large quasi-random number of $\tau$ ranging between 2 and 12 weeks as input of the simulation

$$
\sigma^{\prime}(40)=\frac{1}{M} \sum_{i=1}^{M} \sigma^{\prime}\left(40, \tau_{i}\right)
$$

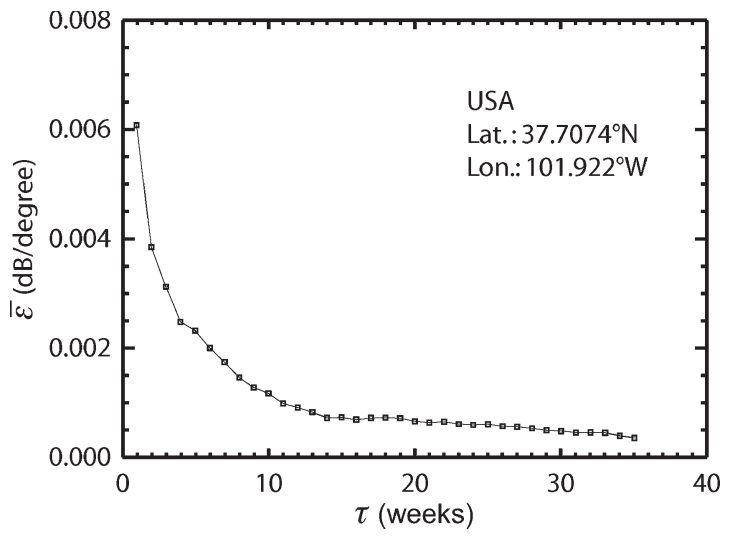

Fig. 6. Noise of slope function decreases by using the larger time-window lengths.

where $M$ is the number of the evaluations in the $\mathrm{MC}$ simulation. The same method used for the slope calculation is applied for the determination of the curvature $\sigma^{\prime \prime}(40)$, the second derivative of $\sigma^{0}(\theta)$ at $40^{\circ}$

$$
\sigma^{\prime \prime}(40)=\frac{1}{M} \sum_{i=1}^{M} \sigma^{\prime \prime}\left(40, \tau_{i}\right) .
$$

Finally, instead of using empirical functions introduced in WARP4, a cubic spline interpolation is performed to obtain the slope and curvature functions $\sigma^{\prime}(40, t)$ and $\sigma^{\prime \prime}(40, t)$. Fig. 7 shows the new slope function calculated for a WARP5 grid point nearest to the location shown in Fig. 3 in Mali, Africa. As another example, in Fig. 8, the slope functions in WARP5 and WARP4 are compared for a grid point located in Kansas, U.S. $\left(37^{\circ} 42^{\prime} 27^{\prime \prime} \mathrm{N}, 101^{\circ} 55^{\prime} 19^{\prime \prime} \mathrm{W}\right)$. The double peaks in the slope function of WARP5, caused in this case by the farming activities in the region, could not be detected by the old method. Such rapid variations of the vegetation canopy within a year can also be observed in vegetation index data. Using the new method, a more accurate fit of the slope function is established, particularly when the biomass reaches its maximum maturity. Fig. 9 shows the time of year when the slope function reaches its highest value in two different algorithms. In some instances, there is a more than ten-day difference in the estimation of the maximum slope.

\section{Dry and Wet Reference Determination}

The TU-Wien model is essentially a change-detection method that relates $\sigma^{0}(40, t)$ to the lowest and highest values of $\sigma^{0}(40)$ that have ever been recorded. The lowest and highest values are supposed to be references of the driest and the wettest conditions of soil surface. A significant step before the determination of the dry/wet references is removing outliers in the $\sigma^{0}(40)$ time series. This should be done cautiously to avoid taking out the valid measurements. The outliers in the $\sigma^{0}(40)$ distribution are representing faulty data because of systematic errors like instrument malfunctioning or situations where the algorithm might not be valid. Such outliers are detected in two individual phases during the calculation of dry/wet references. In the first step, values greater than three interquartile distances 


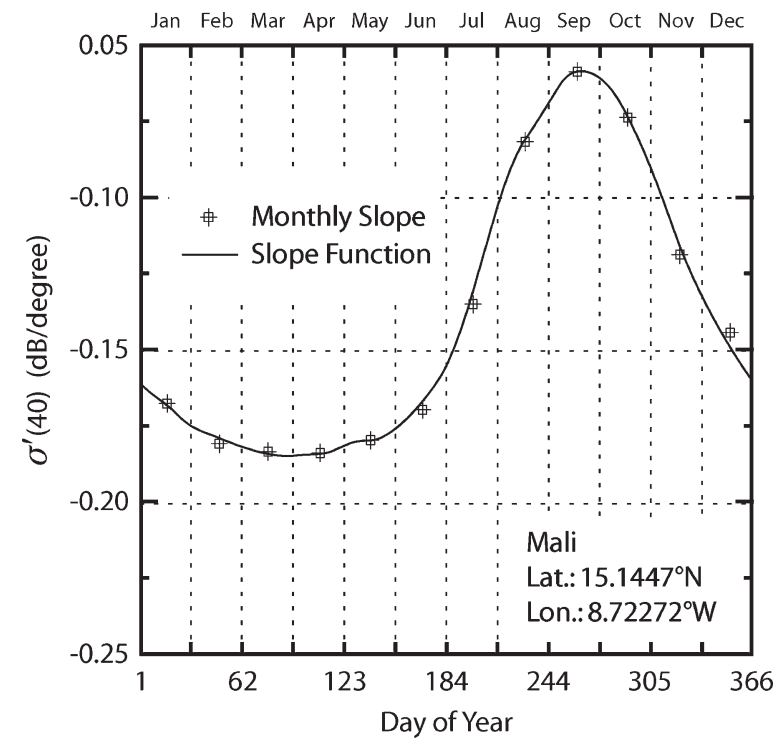

Fig. 7. WARP5 monthly slope values at $40^{\circ}$ and respective slope function.

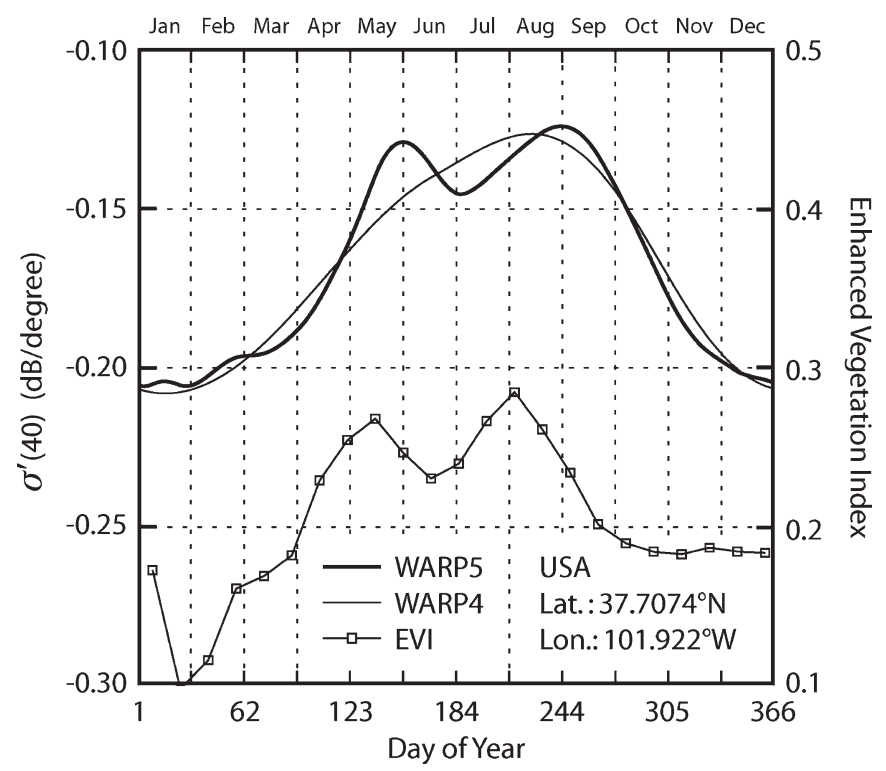

Fig. 8. Slope functions calculated in WARP4 and WARP5 compared with the averaged EVI.

from the mean are removed from the $\sigma^{0}(40)$ distribution. After separating extreme low and high values in the $\sigma^{0}(40)$ distribution, the outlier removal procedure is performed once again to remove outliers greater than 1.5 interquartile distances from the mean, in both groups of the extreme low and high observations.

The backscatter coefficients under dry and wet conditions are estimated by taking an average of the extreme lowest and highest measurements. In WARP4, the number of observations, which are used for the averaging of the extreme measurements, is kept constant, ignoring the regional differences in the noise level. In WARP5, the extreme low values in $\sigma^{0}\left(\theta_{\mathrm{dry}}\right)$ and the extreme high values in $\sigma^{0}\left(\theta_{\text {wet }}\right)$ distributions are separated with respect to an explicit uncertainty range, defined as a $95 \%$ twosided confidence interval of the measurements. The confidence interval of the extreme low and high values is obtained by considering the noise of $\sigma^{0}\left(\theta_{\text {dry }}\right)$ and $\sigma^{0}\left(\theta_{\text {wet }}\right)$

$$
\text { Confidence Interval }= \pm 1.96 \times\left(\text { Noise of } \sigma^{0}(\theta)\right) .
$$

The value 1.96 represents the 97.5 percentile of the standard normal distribution, which is often rounded to 2 for simplicity. Consequently, the mean values of the separated extreme observations are considered as dry and wet references at the presumed crossover angles

$$
\begin{gathered}
C_{\text {dry }}^{0}=\frac{1}{N_{\text {lower }}} \sum_{i=1}^{N_{\text {lower }}} \sigma_{i}^{0}\left(\theta_{\text {dry }}\right) \\
C_{\text {wet }}^{0}=\frac{1}{N_{\text {upper }}} \sum_{i=1}^{N_{\text {upper }}} \sigma_{i}^{0}\left(\theta_{\text {wet }}\right)
\end{gathered}
$$

where $N_{\text {lower }}$ and $N_{\text {upper }}$ are the numbers of low and high extreme values in the $\sigma^{0}\left(\theta_{\text {dry }}\right)$ and $\sigma^{0}\left(\theta_{\text {wet }}\right)$ distributions, respectively.

Knowing $C_{\mathrm{dry}}^{0}$ and $C_{\mathrm{wet}}^{0}$ and considering (2), dry and wet references at $40^{\circ}$ are obtained as follows:

$$
\begin{aligned}
\sigma_{\mathrm{dry}}^{0}(40, t)= & C_{\mathrm{dry}}^{0}-\sigma^{\prime}(40, t)\left(\theta_{\mathrm{dry}}-40\right) \\
& -\frac{1}{2} \sigma^{\prime \prime}(40, t)\left(\theta_{\mathrm{dry}}-40\right)^{2} \\
\sigma_{\mathrm{wet}}^{0}(40, t)= & C_{\mathrm{wet}}^{0}-\sigma^{\prime}(40, t)\left(\theta_{\mathrm{wet}}-40\right) \\
& -\frac{1}{2} \sigma^{\prime \prime}(40, t)\left(\theta_{\mathrm{wet}}-40\right)^{2} .
\end{aligned}
$$

Equations (18) and (19) imply that the dry and wet references vary during the year, depending on the incidence angle deviation from the dry/wet crossover angles and also the condition of vegetation canopy, which is reflected in the slope and curvature. This comprises a vegetation correction in soil moisture estimation if the crossover angles are chosen correctly. In WARP algorithm, crossover angles are set to $\theta_{\text {wet }}=40^{\circ}$ and $\theta_{\mathrm{dry}}=25^{\circ}$. This generates a constant wet reference but a dynamic dry reference. Fig. 10 shows the dry/wet references calculated in WARP5 together with the cumulative distribution of $\sigma^{0}(40)$ for a grid point in Spain.

In WARP5, a new empirical bias-correction factor based on sensitivity $\left(\sigma_{\text {wet }}^{0}-\sigma_{\text {dry }}^{0}\right)$ is applied to $\sigma_{\text {wet }}^{0}(40)$ values in areas where the saturation condition is probably never observed, which is identified by the external climate data [51]. In such areas, $\sigma_{\text {wet }}^{0}(40)$ values are raised until the sensitivity reaches to at least $5 \mathrm{~dB}$. Although the new correction factor provides a more spatially uniform wet correction, it is still an interim solution like the earlier method.

\section{E. Noise Model}

The degree of accuracy and reliability of the soil moisture product, as output of the WARP processor, depends on the retrieval algorithm functionality in addition to the noise of the scatterometer observations. In WARP5, parallel to the soil moisture retrieval algorithm, an error analysis is carried out to determine the uncertainties associated with the measurements 


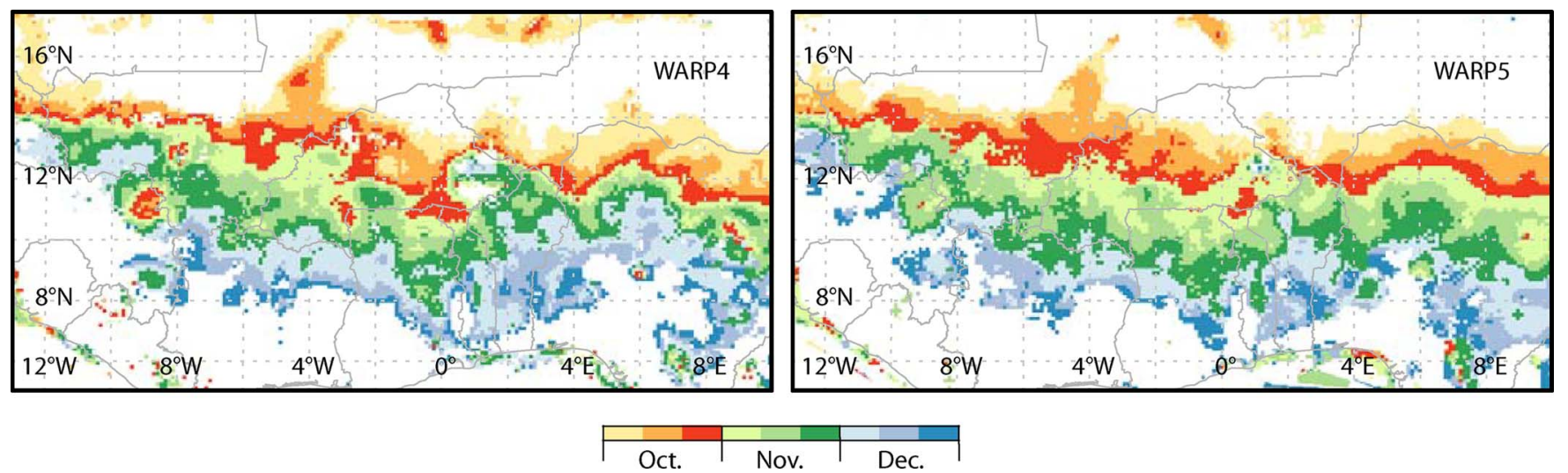

Fig. 9. Time of the year when the slope parameter reaches its maximum value across the Sahelian zone in Africa.

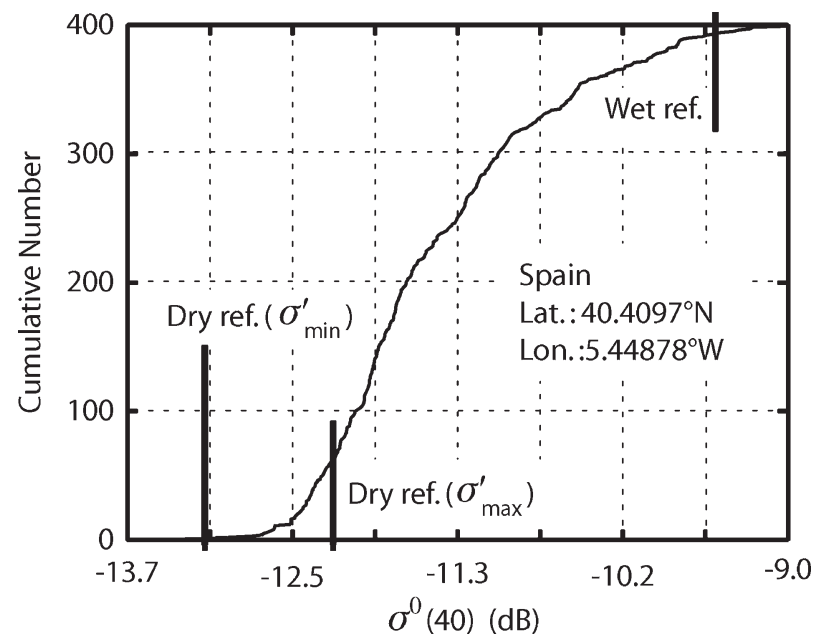

Fig. 10. Cumulative distribution of the normalized backscatter and determination of the dry/wet references.

and the model parameters. The noise model is initialized with the azimuthal noise, which is calculated using (10), and propagated through the retrieval algorithm. Using such an error propagation procedure, the uncertainties in the measured variables are carried over to determine the final surface soil moisture noise $\varepsilon_{\Theta s}$. The following approximation of an error propagation equation [52] is used throughout the processing steps:

$$
\varepsilon_{\Theta s}^{2} \approx \sum_{i=1}^{n}\left(\frac{\partial f}{\partial p_{i}}\right)^{2} \cdot \varepsilon_{p_{i}}^{2}
$$

where $\Theta_{s}=f\left(p_{1}, \ldots, p_{n}\right)$ and $\varepsilon_{p_{i}}$ is the estimated noise of the model parameter $p_{i}$, assuming that the parameters in the model are uncorrelated.

The noise of soil moisture retrieved from the scatterometer data comprises errors coming from the instrument, azimuthal anisotropy, speckle, as well as the uncertainties associated with the model parameters. In the TU-Wien noise model, a range of possible error sources are taken into account. There are a variety of factors influencing the noise of relative soil moisture that can be categorized as variables depending on the time of year (sensitivity and noise of slope and curvature parameters), invariable in time (ESD), and parameters dependent on data acquisition, including $\sigma^{0}$ and the extent of incidence angle deviation from the reference incidence angle. Fig. 11 shows the global maps of ESD after azimuthal correction, sensitivity, and the averaged value of the estimated soil moisture noise. The estimated soil moisture noise identifies areas where the algorithm does not work properly. This includes areas with dense vegetation cover, sand deserts, coastal areas, water bodies, areas covered with permanent snow or ice, and areas with complex topography.

One should bear in mind that the WARP5 noise model is able to estimate the entire errors related to soil moisture if the basic assumptions in the retrieval algorithm are valid. However, some nonsystematic error sources resulting from snow cover or frozen surface remain unpredictable. Such errors cannot be detected with the noise model and should be carefully flagged or masked using some external data sets.

\section{EVALUATION OF WARP5}

To evaluate the impact of the model changes on the soil moisture estimates, we compare the derived soil moisture with the in situ soil moisture observations from the Mesonet network located in Oklahoma, U.S., and with the global reanalysis soil moisture data from the ERA-Interim project.

\section{A. Comparison With In Situ Soil Moisture Observations}

1) Study Area: Oklahoma state is located in the south central region of the U.S. covering an area of $181196 \mathrm{~km}^{2}$. Forests cover $24 \%$ of the area, and a broad band of prairie and steppe shelter expansive ecosystems in the state's central and western portions, although cropland has largely replaced native grasses. Fig. 12(a) shows the region's land cover [53]. Oklahoma is situated between the Great Plains and the Ozark Plateau in the Gulf of Mexico watershed, sloping from the high plains in the west to the southeastern low wetlands. The highest peak is Black Mesa (1516 m above sea level), located in the northwest corner in the Oklahoma Panhandle, and the state's lowest point is on the Little River near its far southeastern boundary ( $88 \mathrm{~m}$ above sea level).

Oklahoma is placed in a temperate region with a continental climate. Because of its position between zones of differing prevailing temperature and winds, weather patterns within the state can vary widely between relatively short distances. The southern and eastern portions of the state are influenced heavily 

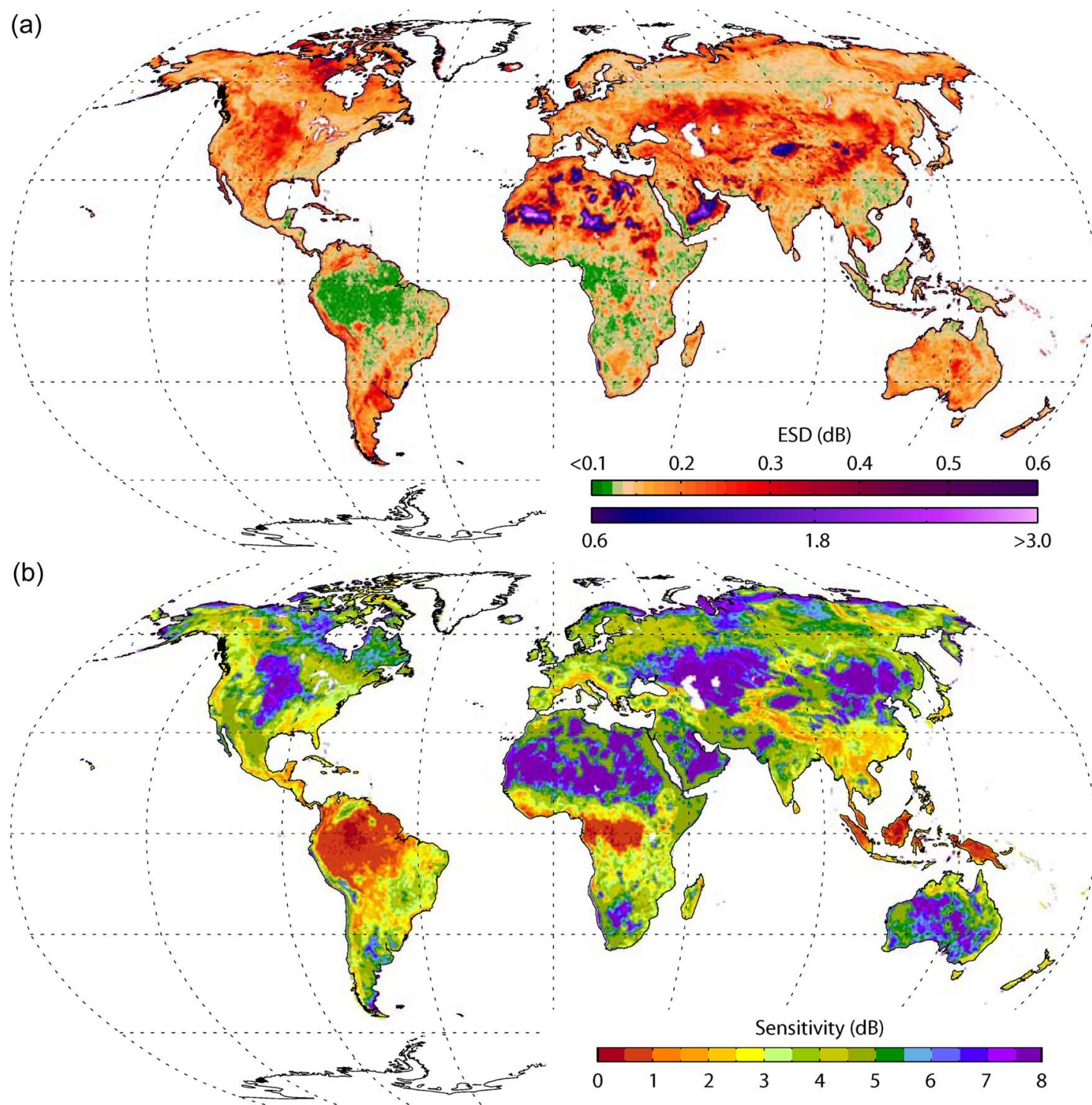

0.6

1.8

3.0

(c)

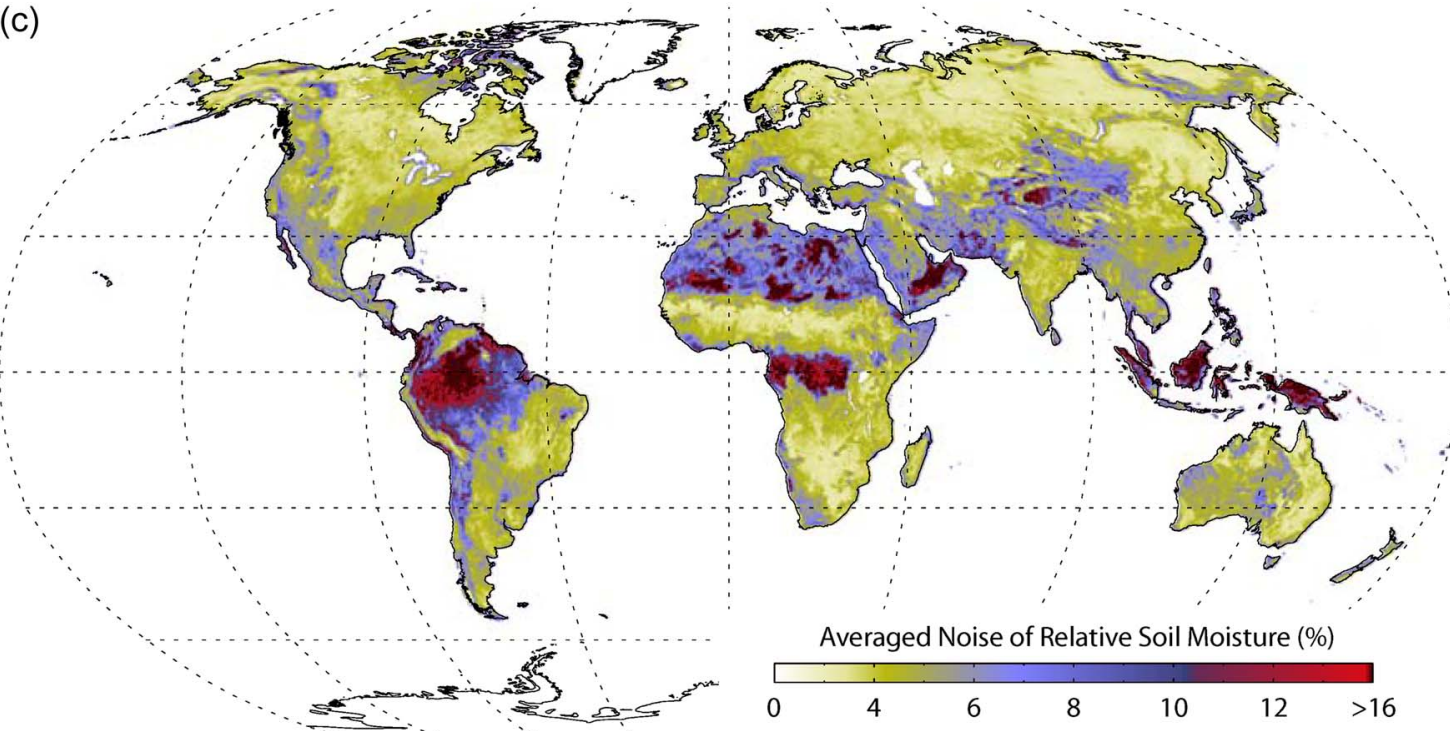

Fig. 11. (a) ESD of backscatter. (b) Sensitivity $\left(\sigma_{\text {wet }}^{0}-\sigma_{\text {dry }}^{0}\right)$. (c) Average of the estimated soil moisture noise. 
(a)

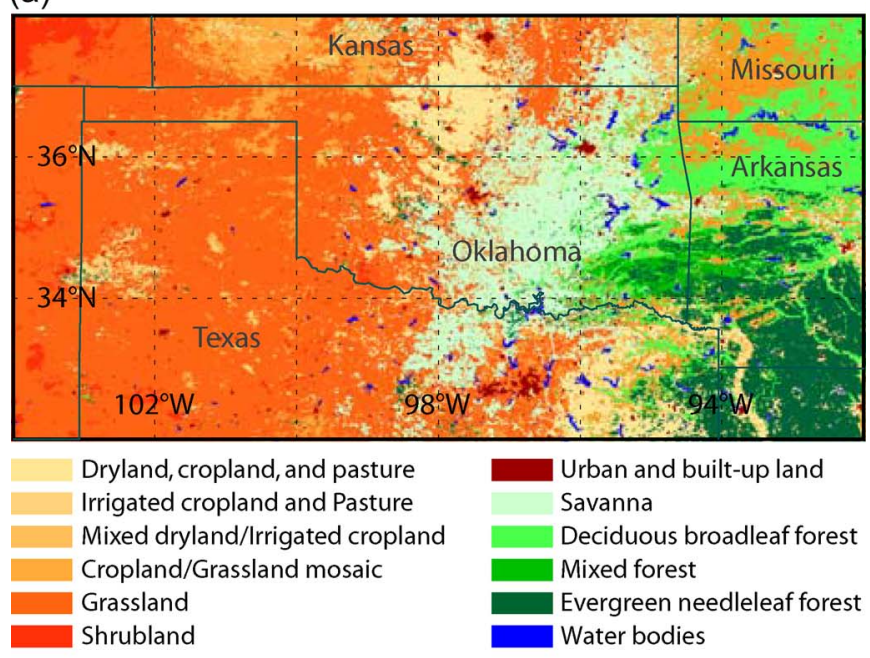

(b)
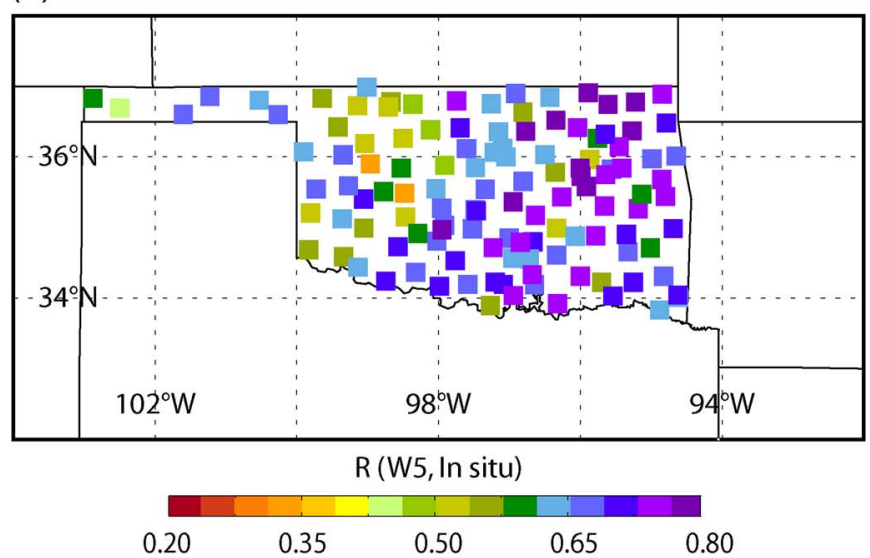

(c)
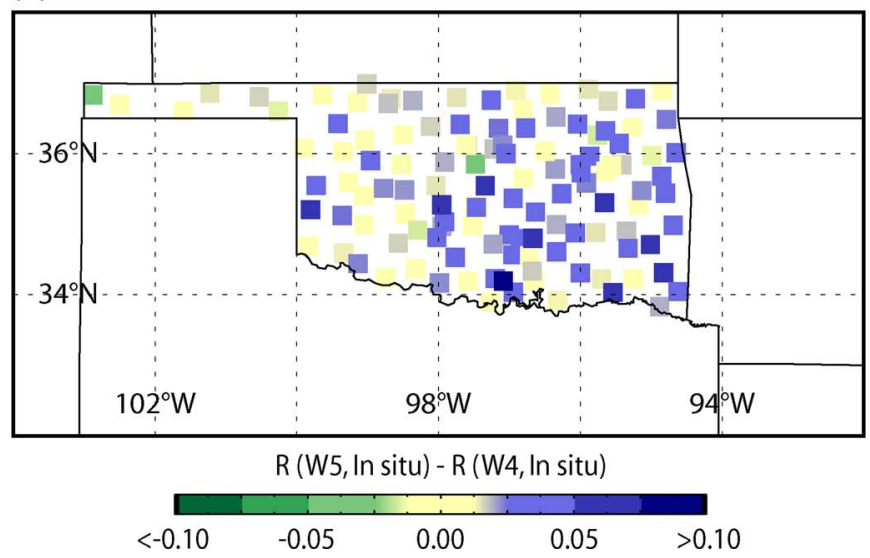

Fig. 12. (a) Oklahoma state's land cover [53]. (b) Correlation coefficients between WARP5 soil moisture data and in situ observations. (c) Difference of the correlation coefficients obtained from comparing WARP4 and WARP5 data with in situ observations.

by warm and humid air moving northward from the Gulf of Mexico but transitions to a semiarid zone in the western parts and the high plains of the Panhandle are less frequently affected by southern moisture. Precipitation and temperature fall from east to west accordingly. The southeast areas have an annual average temperature of $17^{\circ} \mathrm{C}$ and an annual rainfall of $1420 \mathrm{~mm}$, while in areas of the Panhandle, the average temperature is $14{ }^{\circ} \mathrm{C}$, and annual rainfall is under $430 \mathrm{~mm}$. In the Oklahoma region, summers are long and usually quite hot. Winters are shorter and less rigorous than those of the more northern states. Periods of extreme cold are infrequent, and those lasting more than a few days are rare [54].

2) Mesonet Network: The Oklahoma Mesonet is a network of 127 automated meteorological monitoring sites including soil moisture sensing devices [55]. Stations are distributed across Oklahoma with at least one station in every county providing real-time data. The soil moisture sensors installed at Oklahoma Mesonet sites are heat dissipation sensors manufactured by Campbell Scientific known as 229-L and deployed at four different depths $(5,25,60$, and $75 \mathrm{~cm}$ below the surface). Data are collected every $30 \mathrm{~min}$, and a series of automated and manual processes performs a quality control and convert the raw data into daily average values. The $229-\mathrm{L}$ sensors measure a temperature difference, which is the change in sensor temperature after a heat pulse has been introduced [56]. Because the specific heat and thermal conductivity of water are different from that of the porous ceramic matrix, the magnitude of heat dissipation varies with varying contents of soil water. Thus, a constant interval of heating leads to different temperature rises depending upon the water content of the soil. The soil water content depends strongly on soil texture while soil matric potential is exponentially related to soil wetness. Therefore, a normalized parameter of the sensor response called fractional water index (FWI) is used to measure soil moisture dynamics. FWI is a unitless value ranging from zero for very dry soil to one for soil at field capacity. FWI is a linear quantity, which is not limited by varying soil texture at each site [57].

3) Results of Comparison: In this paper, we used the 5-cm-layer FWI measurements in a period of three years (2004-2006). In situ measurements are fairly accurate but they are point measurements. Since soil moisture has an extreme spatial variability behavior at small scale, it is very difficult to estimate catchment average soil moisture from such point measurements [58]. Therefore, a comparison of in situ observations with scatterometer data can be reasonable only if the in situ data are linked to the atmospheric-forcing-related component of soil moisture at regional scale. Fig. 12(b) shows the correlation coefficients between in situ and WARP5 soil moisture data. As it is expected, lower correlation coefficients are observable in irrigated cropland areas, where point measurements usually do not follow the regional averages. In general, the comparison of in situ data with WARP5 and WARP4 soil moisture measurements indicates remarkable improvements in soil moisture estimation using the new algorithm. The difference in correlation coefficients in some stations is up to 0.1 [Fig. 12(c)].

\section{B. Comparison With ERA-Interim Reanalysis Data Set}

Using modeled soil moisture to evaluate satellite observations is problematic. Robock et al. [59] noted that the agreement of both the amplitude and the interannual variation of soil moisture between 30 different atmospheric general circulation models was poor. However, strengths and weaknesses of the modeled and observed data sets are well understood, and it should be possible to draw "intelligent conclusions" in each case. In addition, the intention here was not to determine the 

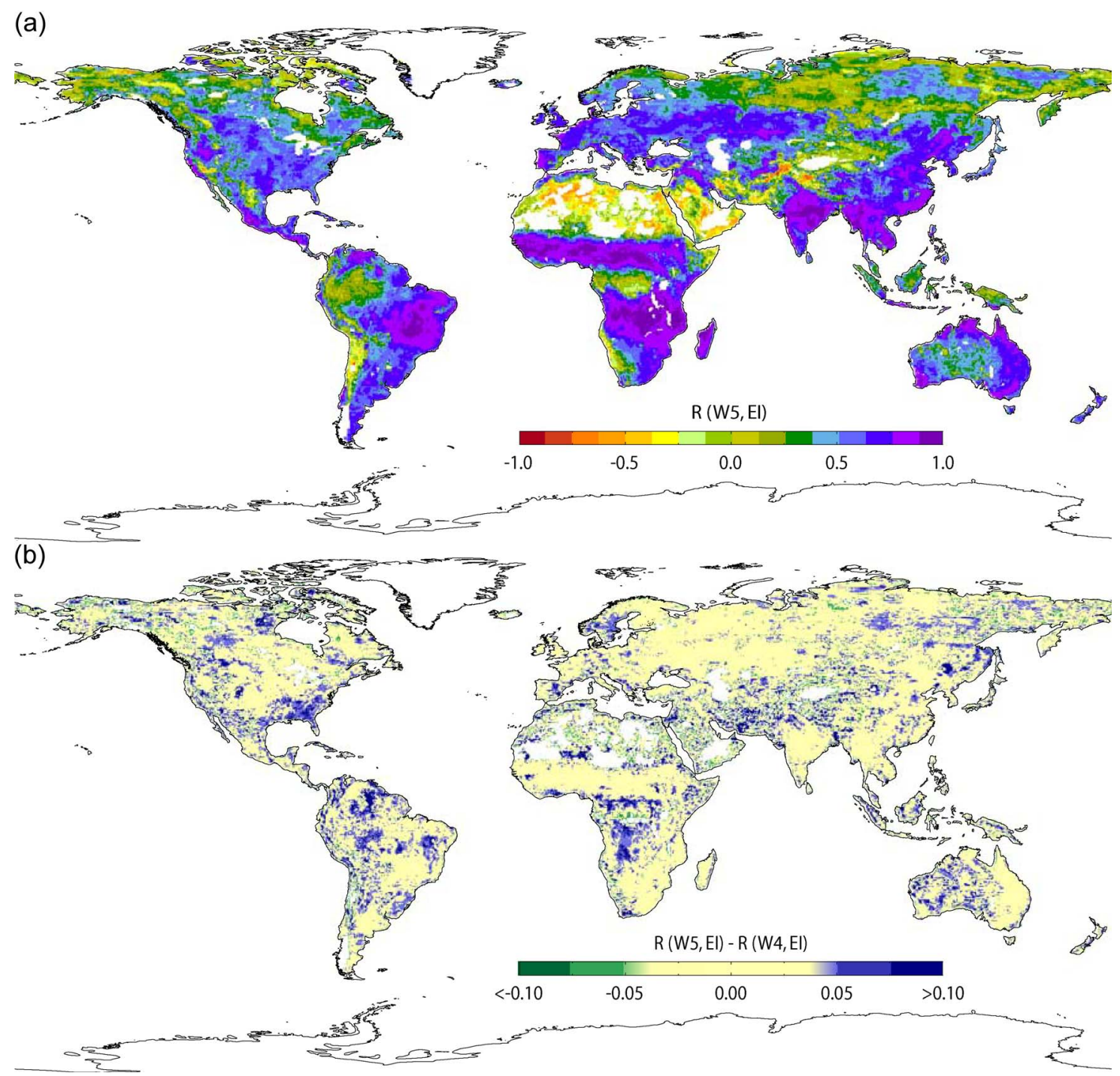

Fig. 13. (a) Correlation coefficients (R) between WARP5 and ERA-Interim soil moisture data. (b) Difference of correlation coefficients between ERA-Interim and WARP5 compared to the correlation between ERA-Interim and WARP4.

absolute accuracy of the scatterometer soil moisture data but to evaluate how changes in the retrieval improve the soil moisture estimation. Nevertheless, interpretation of the results has to be done carefully. While an improvement in the correlation between WARP5 and ERA-Interim soil moisture compared to the correlations observed between WARP4 and ERA-Interim does not necessarily indicate a more accurate soil moisture retrieval, a degradation does not mean that the retrieval is less accurate.

ERA-Interim is based on the ECMWF Integrated Forecast Model, a global numerical weather prediction model. The data set used in this paper covers the entire lifetime of the ERS satellites and is an advanced version of the widely used ERA40 reanalysis data set [60]. ERA-Interim uses mostly the sets of observations acquired for ERA-40, supplemented by data for later years from ECMWF's operational archive. The data have a spatial resolution of $50 \mathrm{~km}$. Land surface processes are described by the Tiled ECMWF Scheme for Surface Exchanges over Land [61], [62]. Soil moisture is analyzed everyday at 00, 06, 12, and 18 Coordinated Universal Time (UTC) using an optimum interpolation scheme of screen-level observations. To

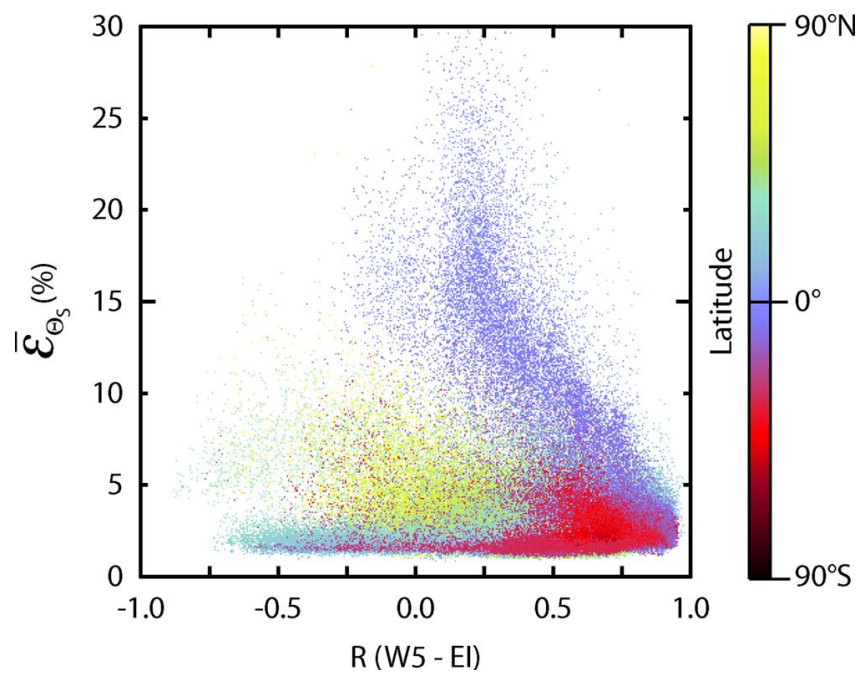

Fig. 14. Correlation between WARP5 and ERA-Interim soil moisture data increases clearly by decreasing the estimated soil moisture retrieval noise excluding the higher latitudes. 


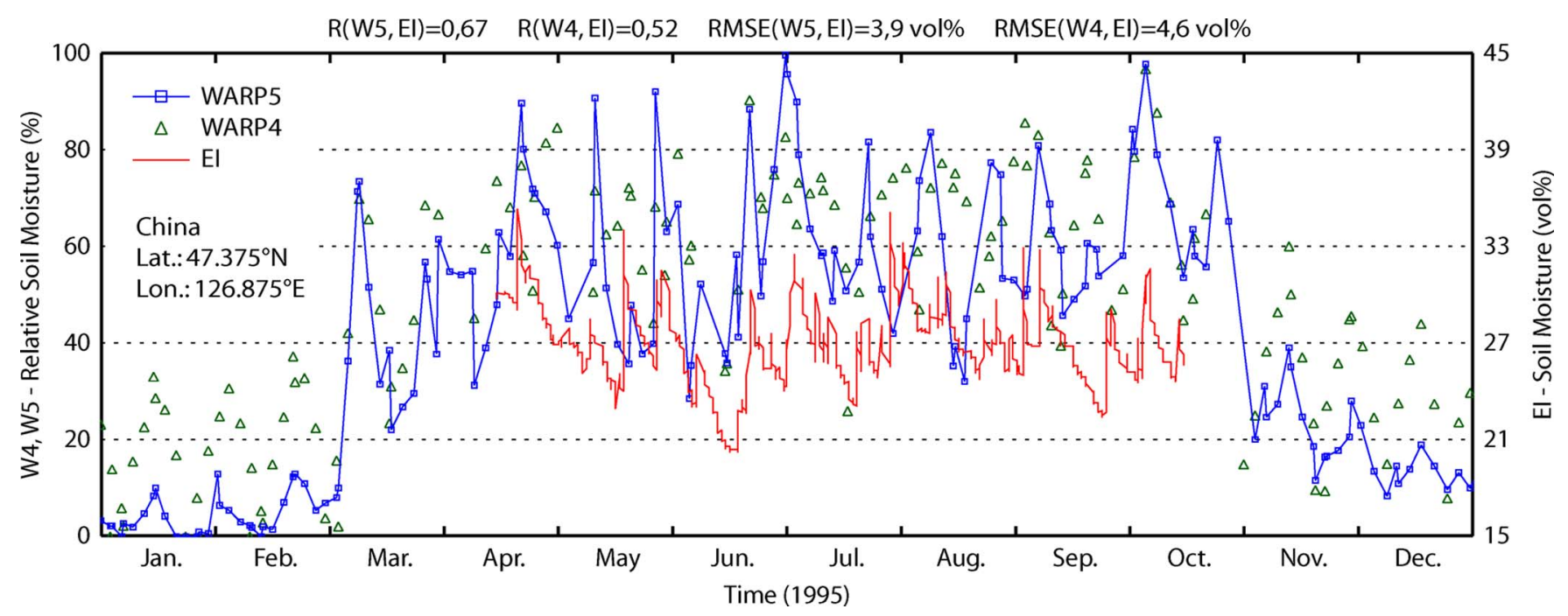

Fig. 15. Time series of WARP4, WARP5, and ERA-Interim soil moisture measurements.

facilitate the comparison, each data set has been collocated to a regular $0.25^{\circ}$ grid using a nearest neighbor resampling method, and satellite observations have been pooled into six hourly files. Observations were masked if one of the data sets indicated missing observations or if the ERA-Interim reanalysis indicated freezing or snow-covered conditions. Fig. 13(a) shows the correlation between the modeled and satellite-observed soil moisture (WARP5), and Fig. 13(b) shows areas where the correlation coefficients are improved using the new algorithm. In general, the correlation is positive over large parts of the land surface, with maximum values around 0.9 . At $85 \%$ of the land points, the correlation is significant at the 0.05 level, at $8 \%$ of the land points, soil moisture is not correlated significantly, and at $7 \%$, the correlation is negative at the 0.05 confidence level according to a t-test. The spatial distribution of the correlation clearly reflects zonal climate patterns. As expected, the correlation is high in areas characterized by a strong seasonal soil moisture cycle (for example, in Monsoon areas). Over deserts, the correlation becomes negative. This problem has also been reported by Wagner et al. [24] and can be attributed to a shortcoming in the satellite retrieval method. The maps also exhibit some unexpected features. Over Europe, the correlation is comparably high. Similarly, the correlation is high over Southeast China which is supposed to be characterized by a low sensitivity of the microwave signal to soil moisture due to a high amount of above-ground biomass. The high correlations over Spain are specifically encouraging. The climate has a wet winter and a dry summer. Consequently, soil moisture and vegetation behave quasi-anticyclically, while in the other climate types, vegetation and soil moisture are often highly correlated. Under the latter conditions, imperfections in the backscatter model may be hidden because vegetation may act as a proxy indicator for soil moisture or vice versa. Over Spain, such imperfections of the retrieval method would yield inconsistent results. Some part of the discrepancy between the modeled and SCAT data can be described by the estimated retrieval noise. Fig. 14 shows how the correlation between ERA-Interim and WARP5 data decreases by increasing the retrieval noise in lower latitudes.

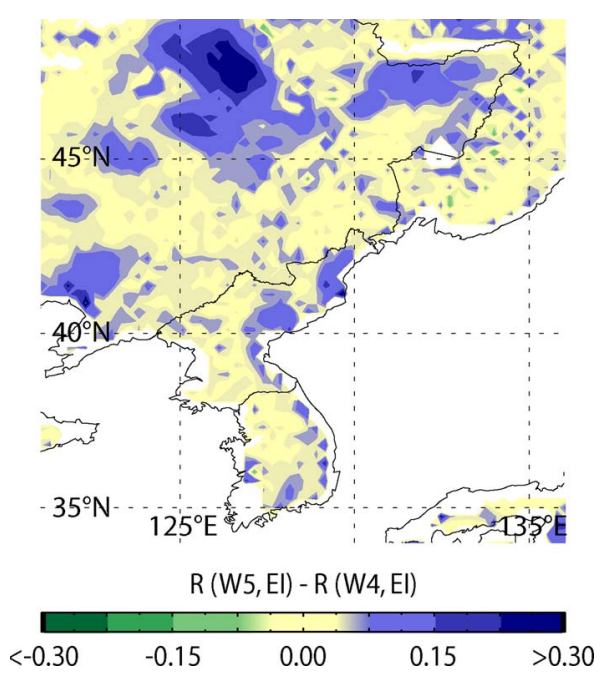

Fig. 16. Northwestern China. Higher correlation between ERA-Interim and WARP5 is regionally observable compared to the correlation between ERAInterim and WARP4.

Fig. 15 shows an example of how the new processing scheme works in practice in an area affected by strong azimuthal effects. This is a soil moisture time series over northwestern China, an area heavily affected by azimuthal viewing effects due to largescale farming activities [47]. These effects are most clearly visible during winter. During this time, the soil is frozen, and temperatures are well below $0{ }^{\circ} \mathrm{C}$. For the scatterometer the frozen soil appears comparable to a completely dry soil. The variation visible in the soil moisture signal is therefore completely artificial, caused by azimuthal anisotropies. In WARP4, processing this variation can make up to $40 \%$. In WARP5, the effect is substantially lowered to a value of $10 \%$. Also, during summer, the improved functioning of the retrieval is confirmed by a better fit of satellite observations to modeled soil moisture. Consequently, the correlation coefficients in this region increase up to more than 0.2 (Fig. 16). The new processing also leads to spatially more consistent soil moisture estimates. Fig. 17 shows an example over the southeastern parts of the U.S. Over this area, a biased estimation of the wet reference leads to too dry 

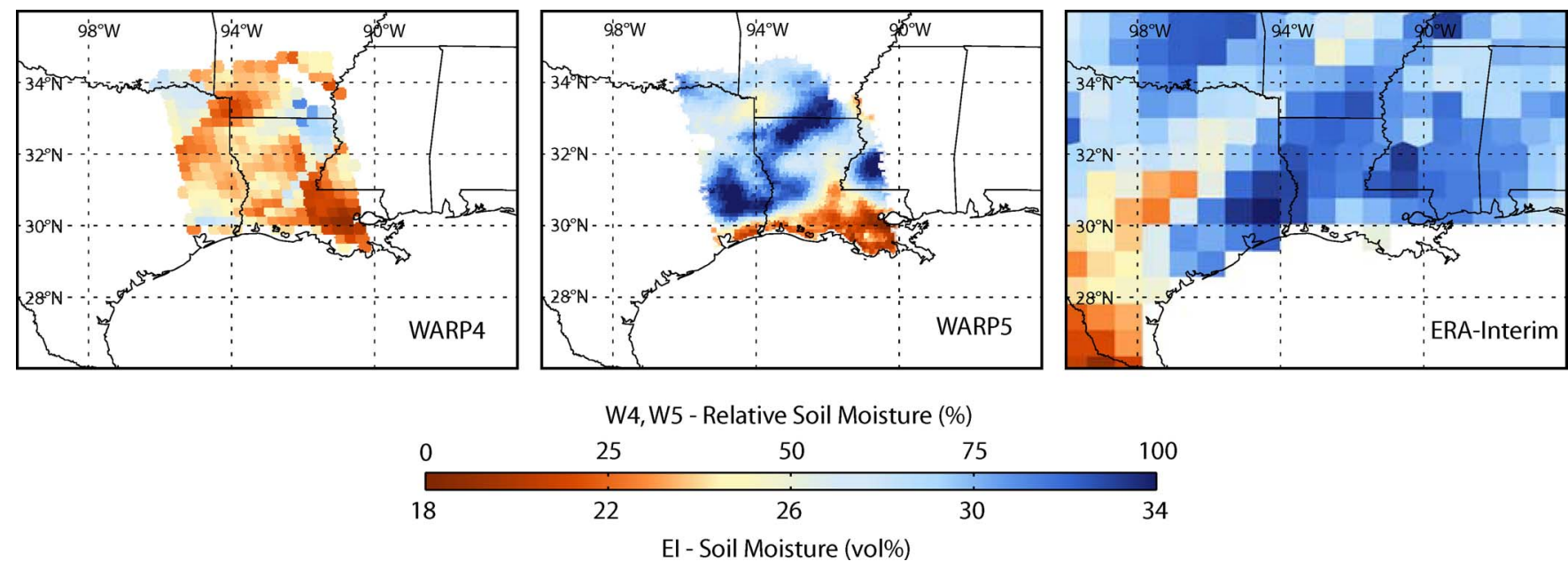

Fig. 17. Southeastern U.S. Comparison of soil moisture data sets as an example of improvement in soil moisture estimation with the new algorithm WARP5.
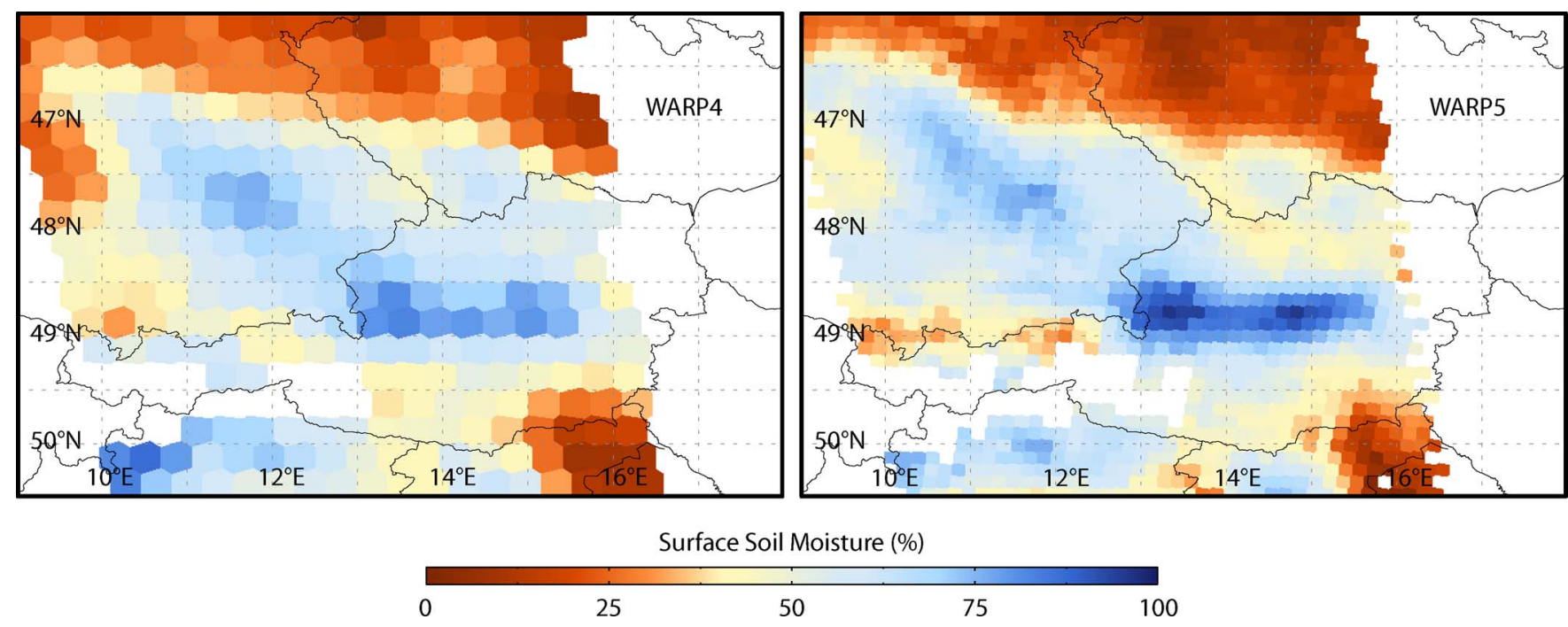

Fig. 18. Central Europe. Comparison of WARP4 and WARP5 soil moisture data.

soil moisture estimates compared to the adjacent regions. The soil moisture patterns are spatially more consistent and compare well to the modeled soil moisture.

\section{SUMmARY AND OUTLOOK}

In this paper, we introduced an enhanced algorithm for the derivation of the relative soil moisture from scatterometer data. We have addressed some limitations of the earlier processing algorithm WARP4 and proposed a new methodology to improve the TU-Wien model parameterization. The improvements gained by the new algorithm result in a more uniform performance of the model and, consequently, a spatially consistent soil moisture product with a better resolution (Fig. 18). The artificial variations in soil moisture caused by the azimuthal effects are effectively weakened through the azimuthal correction method. The MC simulation performed in the new algorithm made it possible to approach to an optimal time-window length for slope parameter calculations. A more accurate and sensitive slope function is succeeded by the new formulation of the slope. This is important as the seasonal vegetation dynamics is the most important parameter in the normalization of the backscattered signal and is also essential for the vegetation correction procedure. The WARP5 error analysis not only provides quality information about the product but also helps to improve the calculation of model parameters during the retrieval process. Dry and wet references, determined based on the noise of signal, approximate truthful extreme events and therefore result in spatially uniform references for scaling normalized backscatter. The comparison of satellite data with Mesonet in situ observations and ERA-Interim modeled data confirms the improvements made in the new algorithm particularly in regions characterized with high azimuthal noise.

Although the new method yields several significant improvements, the results show that more work is required on soil moisture retrieval over deserts to understand the complex backscatter mechanism in such regions. The determination of the right dry/wet crossover angles is important and remains to be fully investigated as they impact considerably the calculation of the dry/wet references as well as the vegetation correction procedure. More work is also needed for the correction of wet references in the areas where soil never reaches the saturation point. 


\section{REFERENCES}

[1] D. Klaes and K. Holmlund, "The EPS/Metop system: Overview and first results," in Proc. Joint EUMETSAT Meteorol. Satell. Conf., 15th Satell. Meteorol. Oceanogr. Conf. Amer. Meteorol. Soc., Amsterdam, The Netherlands, 2007.

[2] J. Figa-Saldana, J. J. W. Wilson, E. Attema, R. Gelsthorpe, M. R. Drinkwater, and A. Stoffelen, "The Advanced Scatterometer (ASCAT) on the meteorological operational (MetOp) platform: A follow on for European wind scatterometers," Can. J. Remote Sens., vol. 28, pp. 404-412, 2002.

[3] H. Hersbach, A. Stoffelen, and S. De Haan, "An improved C-band scatterometer ocean geophysical model function: CMOD5," J. Geophys. Res. C, Oceans, vol. 112, no. C3, pp. C03 006.1-C03 006.18, Mar. 2007.

[4] P. L. Frison, E. Mougin, and P. Hiernaux, "Observations and interpretation of seasonal ERS-1 wind scatterometer data over northern Sahel (Mali)," Remote Sens. Environ., vol. 63, no. 3, pp. 233-242, Mar. 1998.

[5] J. T. Pulliainen, T. Manninen, and M. T. Hallikainen, "Application of ERS-1 wind scatterometer data to soil frost and soil moisture monitoring in boreal forest zone," IEEE Trans. Geosci. Remote Sens., vol. 36, no. 3, pp. 849-863, May 1998.

[6] I. H. Woodhouse and D. H. Hoekman, "Determining land-surface parameters from the ERS wind scatterometer," IEEE Trans. Geosci. Remote Sens., vol. 38, no. 1, pp. 126-140, Jan. 2000.

[7] R. D. Magagi and Y. H. Kerr, "Estimating surface soil moisture and soil roughness over semiarid areas from the use of the copolarization ratio," Remote Sens. Environ., vol. 75, no. 3, pp. 432-445, Mar. 2001.

[8] L. Jarlan, P. Mazzega, and E. Mougin, "Retrieval of land surface parameters in the Sahel from ERS wind scatterometer data: A 'brute force' method," IEEE Trans. Geosci. Remote Sens., vol. 40, no. 9, pp. 20562062, Sep. 2002.

[9] S. Zine, L. Jarlan, P. L. Frison, E. Mougin, P. Hiernaux, and J. P. Rudant, "Land surface parameter monitoring with ERS scatterometer data over the Sahel: A comparison between agro-pastoral and pastoral areas," Remote Sens. Environ., vol. 96, no. 3/4, pp. 438-452, Jun. 2005.

[10] Y. Oh, K. Sarabandi, and F. T. Ulaby, "An empirical model and an inversion technique for radar scattering from bare soil surfaces," IEEE Trans. Geosci. Remote Sens., vol. 30, no. 2, pp. 370-381, Mar. 1992.

[11] A. K. Fung, Z. Q. Li, and K. S. Chen, "Backscattering from a randomly rough dielectric surface," IEEE Trans. Geosci. Remote Sens., vol. 30, no. 2, pp. 356-369, Mar. 1992.

[12] E. P. W. Attema and F. T. Ulaby, "Vegetation modeled as a water cloud," Radio Sci., vol. 13, no. 2, pp. 357-364, 1978.

[13] E. Mougin, D. Loseen, S. Rambal, A. Gaston, and P. Hiernaux, "A regional Sahelian grassland model to be coupled with multispectral satellite data. I: Model description and validation," Remote Sens. Environ., vol. 52, no. 3, pp. 181-193, Jun. 1995.

[14] M. W. J. Davidson, T. Le Toan, F. Mattia, G. Satalino, T. Manninen, and M. Borgeaud, "On the characterization of agricultural soil roughness for radar remote sensing studies," IEEE Trans. Geosci. Remote Sens., vol. 38, no. 2 , pp. 630-640, Mar. 2000.

[15] M. Grippa and I. H. Woodhouse, "Validation of surface scattering models across large footprints for global scatterometer applications," IEEE Trans. Geosci. Remote Sens., vol. 40, no. 10, pp. 2229-2233, Oct. 2002.

[16] W. Wagner, G. Lemoine, and H. Rott, "A method for estimating soil moisture from ERS scatterometer and soil data," Remote Sens. Environ., vol. 70, no. 2, pp. 191-207, Nov. 1999.

[17] B. Moeremans and S. Dautrebande, "Soil moisture evaluation by means of multi-temporal ERS SAR PRI images and interferometric coherence," J. Hydrol., vol. 234, no. 3/4, pp. 162-169, Jul. 2000.

[18] A. Quesney, S. Le Hegarat-Mascle, O. Taconet, D. Vidal-Madjar, J. P. Wigneron, C. Loumagne, and M. Normand, "Estimation of watershed soil moisture index from ERS/SAR data," Remote Sens. Environ., vol. 72, no. 3, pp. 290-303, Jun. 2000.

[19] M. S. Moran, D. C. Hymer, J. G. Qi, and E. E. Sano, "Soil moisture evaluation using multi-temporal synthetic aperture radar (SAR) in semiarid rangeland," Agric. For. Meteorol., vol. 105, no. 1, pp. 69-80, Nov. 2000.

[20] S. Le Hegarat-Mascle, M. Zribi, F. Alem, A. Weisse, and C. Loumagne, "Soil moisture estimation from ERS/SAR data: Toward an operational methodology," IEEE Trans. Geosci. Remote Sens., vol. 40, no. 12, pp. 2647-2658, Dec. 2002.

[21] K. De Ridder, "Quantitative estimation of skin soil moisture with the Special Sensor Microwave/Imager," Boundary-Layer Meteorol., vol. 96, no. 3, pp. 421-432, Sep. 2000.

[22] E. G. Njoku, W. J. Wilson, S. H. Yueh, S. J. Dinardo, F. K. Li, T. J. Jackson, V. Lakshmi, and J. Bolten, "Observations of soil moisture using a passive and active low-frequency microwave airborne sensor dur- ing SGP99," IEEE Trans. Geosci. Remote Sens., vol. 40, no. 12, pp. 2659 2673, Dec. 2002.

[23] K. Scipal, "Global soil moisture monitoring using ERS scatterometer data," Ph.D. dissertation, Inst. Photogramm. Remote Sens., Vienna Univ. Technol., Vienna, Austria, 2002.

[24] W. Wagner, K. Scipal, C. Pathe, D. Gerten, W. Lucht, and B. Rudolf, "Evaluation of the agreement between the first global remotely sensed soil moisture data with model and precipitation data," J. Geophys. Res., vol. 108, no. D19, pp. ACL9.1-ACL9.15, 2003.

[25] P. A. Dirmeyer, Z. Guo, and X. Gao, "Comparison, validation, and transferability of eight multiyear global soil wetness products," J. Hydrometeorol., vol. 5, no. 6, pp. 1011-1033, Dec. 2004.

[26] T. Pellarin, J. C. Calvet, and W. Wagner, "Evaluation of ERS scatterometer soil moisture products over a half-degree region in southwestern France," Geophys. Res. Lett., vol. 33, no. 17, p. L17 401, Sep. 2006.

[27] W. T. Crow and X. W. Zhan, "Continental-scale evaluation of remotely sensed soil moisture products," IEEE Geosci. Remote Sens. Lett., vol. 4, no. 3, pp. 451-455, Jul. 2007.

[28] K. Scipal, C. Scheffler, and W. Wagner, "Soil moisture-runoff relation at the catchment scale as observed with coarse resolution microwave remote sensing," Hydrol. Earth Syst. Sci., vol. 9, no. 3, pp. 173-183, 2005.

[29] J. Parajka, V. Naeimi, G. Blöschl, W. Wagner, R. Merz, and K. Scipal, "Assimilating scatterometer soil moisture data into conceptual hydrologic models at the regional scale," Hydrol. Earth Syst. Sci., vol. 10, no. 3, pp. 353-368, May 2006.

[30] B. Fontaine, S. Louvet, and P. Roucou, "Fluctuations in annual cycles and inter-seasonal memory in West Africa: Rainfall, soil moisture and heat fluxes," Theor. Appl. Climatol., vol. 88, no. 1/2, pp. 57-70, Jan. 2007.

[31] A. M. de Wit and C. A. van Diepen, "Crop model data assimilation with the Ensemble Kalman filter for improving regional crop yield forecasts," Agric. For. Meteorol., vol. 146, no. 1/2, pp. 38-56, Sep. 2007.

[32] K. Scipal, M. Drusch, and W. Wagner, "Assimilation of a ERS scatterometer derived soil moisture index in the ECMWF numerical weather prediction system," Adv. Water Resour., vol. 31, no. 8, pp. 1101-1112, Aug. 2008.

[33] S. Hasenauer, W. Wagner, K. Scipal, V. Naeimi, and Z. Bartalis, "Implementation of near real time soil moisture products in the SAF network based on METOP ASCAT data," in Proc. EUMETSAT Meteorol. Satell. Conf., Helsinki, Finland, 2006.

[34] Z. Bartalis, W. Wagner, V. Naeimi, S. Hasenauer, K. Scipal, H. Bonekamp, J. Figa, and C. Anderson, "Initial soil moisture retrievals from the METOP-A Advanced Scatterometer (ASCAT)," Geophys. Res. Lett., vol. 34, no. 20, p. L20 401, Oct. 2007.

[35] E. P. W. Attema, "The active microwave instrument on-board the ERS-1 satellite," Proc. IEEE, vol. 79, no. 6, pp. 791-799, Jun. 1991.

[36] R. B. Blackman and J. W. Tukey, "Particular pairs of windows," in The Measurement of Power Spectra From the Point of View of Communications Engineering. New York: Dover, 1959, pp. 98-99.

[37] W. Wagner, J. Noll, M. Borgeaud, and H. Rott, "Monitoring soil moisture over the Canadian Prairies with the ERS scatterometer," IEEE Trans. Geosci. Remote Sens., vol. 37, no. 1, pp. 206-216, Jan. 1999.

[38] W. Wagner, G. Lemoine, M. Borgeaud, and H. Rott, "A study of vegetation cover effects on ERS scatterometer data," IEEE Trans. Geosci. Remote Sens., vol. 37, no. 2, pp. 938-948, Mar. 1999.

[39] A. Huete, K. Didan, T. Miura, E. P. Rodriguez, X. Gao, and L. G. Ferreira, "Overview of the radiometric and biophysical performance of the MODIS vegetation indices," Remote Sens. Environ., vol. 83, no. 1, pp. 195-213, Nov. 2002.

[40] A. K. Fung, Microwave Scattering and Emission Models and Their Applications. Norwood, MA: Artech House, 1994.

[41] O. Taconet, D. Vidal-Majar, C. Emblanch, and M. Normand, "Taking into account vegetation effects to estimate soil moisture from C-band radar measurements," Remote Sens. Environ., vol. 56, no. 1, pp. 52-56, Apr. 1996.

[42] W. Wagner, "Soil moisture retrieval from ERS scatterometer data," Ph.D. dissertation, Inst. Photogramm. Remote Sens., Vienna Univ. Technol., Vienna, Austria, 1998.

[43] F. T. Ulaby, R. K. Moore, and A. K. Fung, Microwave Remote Sensing: Active and Passive, From Theory to Application, vol. 2. Norwood, MA: Artech House, 1982.

[44] D. Hillel, Introduction to Soil Physics. San Diego, CA: Academic, 1998.

[45] P. Lecomte, "The ERS scatterometer instrument and the on-ground processing of its data," in Proc. Emerging Scatterometer Appl. Workshop ESTEC, Noordwijk, The Netherlands, 1998, p. 241.

[46] R. Kidd, "Discrete global grid systems," Inst. Photogramm. Remote Sens., Vienna Univ. Technol., Vienna, Austria, ASCAT Soil Moisture Report Series No. 4, 2005. 
[47] Z. Bartalis, K. Scipal, and W. Wagner, "Azimuthal anisotropy of scatterometer measurements over land," IEEE Trans. Geosci. Remote Sens., vol. 44, no. 8, pp. 2083-2092, Aug. 2006.

[48] D. S. Early and D. G. Long, "Azimuthal modulation of C-band scatterometer over Southern Ocean sea ice," IEEE Trans. Geosci. Remote Sens., vol. 35, no. 5, pp. 1201-1209, Sep. 1997.

[49] V. Naeimi, "WARP5.0 error analysis 1," Inst. Photogramm. Remote Sens., Vienna Univ. Technol., Vienna, Austria, ASCAT Soil Moisture Report Series No. 11, 2006.

[50] H. Niederreiter, Random Number Generation and Quasi-Monte Carlo Methods. Philadelphia, PA: SIAM, 1992.

[51] M. Kottek, J. Grieser, C. Beck, B. Rudolf, and F. Rubel, "World map of the Koppen-Geiger climate classification updated," Meteorologische Zeitschrift, vol. 15, no. 3, pp. 259-263, Jun. 2006.

[52] P. R. Bevington, Data Reduction and Error Analysis for the Physical Sciences. New York: McGraw-Hill, 1969.

[53] GLCC, Global Land Cover Characteristics Data Base, U.S. Geological Survey, 1999, U.S. Geological Survey.

[54] D. Arndt, The Climate of Oklahoma, Norman, OK: Oklahoma Climatological Survey, 2003. [Online]. Available: http://cig.mesonet. org/climateatlas/doc60.html

[55] F. V. Brock, K. C. Crawford, R. L. Elliott, G. W. Cuperus, S. J. Stadler, H. L. Johnson, and M. D. Eilts, "The Oklahoma Mesonet: A technical overview," J. Atmos. Ocean. Technol., vol. 12, no. 1, pp. 5-19, Feb. 1995.

[56] J. B. Basara and T. M. Crawford, "Improved installation procedures for deep-layer soil moisture measurements," J. Atmos. Ocean. Technol., vol. 17, no. 6, pp. 879-884, Jun. 2000.

[57] B. G. Illston, J. B. Basara, and K. C. Crawford, "Seasonal to interannual variations of soil moisture measured in Oklahoma," Int. J. Climatol., vol. 24, no. 15, pp. 1883-1896, Dec. 2004.

[58] A. W. Western, R. B. Grayson, and G. Bloeschl, "Scaling of soil moisture: A hydrologic perspective," Annu. Rev. Earth Planet. Sci., vol. 30, pp. 149-180, May 2002.

[59] A. Robock, C. A. Schlosser, K. Y. Vinnikov, N. A. Speranskaya, J. K. Entin, and S. Qiu, "Evaluation of the AMIP soil moisture simulations," Glob. Planet. Change, vol. 19, no. 1-4, pp. 181-208, Dec. 1998

[60] S. M. Uppala, P. W. KÅllberg, A. J. Simmons, U. Andrae, V. da Costa Bechtold, M. Fiorino, J. K. Gibson, J. Haseler, A. Hernandez, G. A. Kelly, X. Li, K. Onogi, S. Saarinen, N. Sokka, R. P. Allan, E. Andersson, K. Arpe, M. A. Balmaseda, A. C. M. Beljaars, L. van de Berg, J. Bidlot, N. Bormann, S. Caires, F. Chevallier, A. Dethof, M. Dragosavac, M. Fisher, M. Fuentes, S. Hagemann, E. Hólm, B. J. Hoskins, L. Isaksen, P. A. E. M. Janssen, R. Jenne, A. P. McNally, J. F. Mahfouf, J. J. Morcrette, N. A. Rayner, R. W. Saunders, P. Simon, A. Sterl, K. E. Trenberth, A. Untch, D. Vasiljevic, P. Viterbo, and J. Woollen, "The ERA-40 reanalysis," Q. J. R. Meteorol. Soc., vol. 131, no. 162, pp. 2961-3012, Oct. 2005

[61] P. Viterbo and A. C. M. Beljaars, "An improved land surface parameterization scheme in the ECMWF model and its validation," J. Clim., vol. 8, no. 11, pp. 2716-2748, Nov. 1995.

[62] B. J. J. M. Van den Hurk, P. Viterbo, A. C. M. Beljaars, and A. K. Betts, Offline Validation of the ERA-40 Surface Scheme, 2000, p. 43.

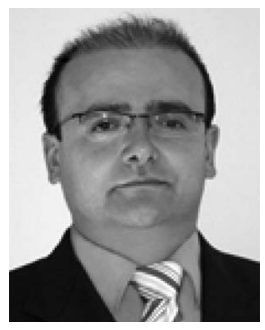

Vahid Naeimi was born in Tehran, Iran, on May 20, 1972. He received the B.Sc. degree in applied physics from Shiraz University, Shiraz, Iran, in 1996, the M.Sc. degree in physical oceanography from Shahid Chamran University, Ahwaz, Iran, in 2001 and the Dr.techn. (Ph.D.) degree in microwave remote sensing, with excellence, from the Vienna University of Technology (TU Wien), Vienna, Austria, in 2009.

Since 2005, he has been working with the Institute of Photogrammetry and Remote Sensing, Vienna University of Technology as a Research Assistant. He has participated in several national and international projects, including GLOBSCAT, GEOLAND, and the development of a processor for ASCAT soil moisture data (EUMETSAT fundet project). His research interests include land surface parameter retrievals for hydrology and climate applications using active microwave remote sensing.

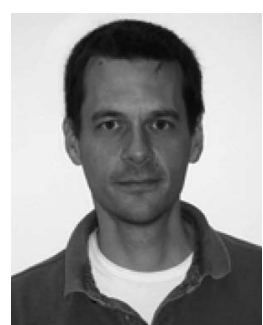

Klaus Scipal (M'08) received the Dipl.Ing. degree in geodesy and the Ph.D. degree in microwave remote sensing from the Vienna University of Technology, Vienna, Austria, in 1999 and 2002, respectively.

Before his Ph.D. degree, for a short period, he was with the Climate Research Branch, Atmospheric Environment Service, Ottawa, Canada. From 2002 to 2006, he was a University Assistant with the Vienna University of Technology, where his main research interest was the retrieval of geophysical parameters from active microwave Earth observation data and their application in hydrology, agrology, and climatology. Since 2006, he has been with the European Centre for Medium-Range Weather Forecasts, Reading, U.K., where he works on data assimilation issues.

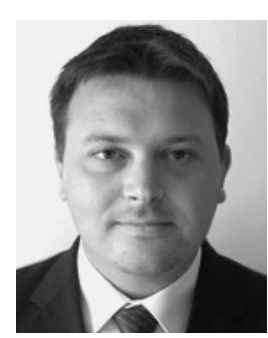

Zoltan Bartalis received the M.S. degree in space engineering from the Luleå University of Technology, Luleå, Sweden, in 2004. He is currently working toward the $\mathrm{Ph} . \mathrm{D}$. degree in active microwave remote sensing of land surfaces in the Institute of Photogrammetry and Remote Sensing, Vienna University of Technology, Vienna, Austria.

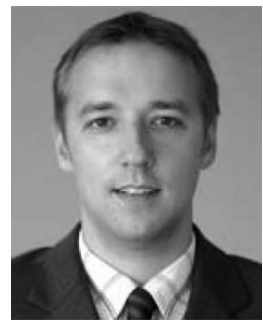

Stefan Hasenauer was born in Villach, Austria, in 1977. He received the M.Sc. degree in environmental system sciences-geography from the University of Graz, Graz, Austria, in 2004 with excellence. He is currently working toward the Ph.D. degree in the Institute of Photogrammetry and Remote Sensing, Vienna University of Technology, Vienna, Austria.

During his studies, he was involved in the European Union project SIBERIA II at the German Aerospace Center, where he was involved in parameter retrieval for greenhouse gas accounting, before joining the Vienna University of Technology in 2004. He is currently involved in the project H-SAF (European Organization for the Exploitation of Meteorological Satellites), and his research interests include bio- and geophysical parameter retrieval from synthetic aperture radar data, scaling issues, and data assimilation strategies.

Mr. Hasenauer is a member of the European Geophysical Union.

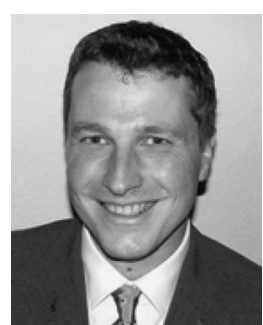

Wolfgang Wagner (M'98-SM'07) was born in Wels, Austria, in 1969. He received the Dipl.Ing. (M.Sc.) degree in physics and the Dr.techn. (Ph.D.) degree in remote sensing, both with excellence, from the Vienna University of Technology (TU Wien), Vienna, Austria, in 1995 and 1999, respectively.

From 1999 to 2001, he was with the German Aerospace Center, first as a Project Assistant with the Institute of High Frequency Technology and later as the Head of the Synthetic Aperture Radar (SAR) Applications team, German Remote Sensing Data Center. In 2001, he was appointed Professor for remote sensing with the Institute of Photogrammetry and Remote Sensing, TU Wien, where he has been the Head since 2006. His main research interest lies in geophysical parameter retrieval techniques from remote sensing data and application development. $\mathrm{He}$ focuses on active remote sensing techniques, particularly scatterometry, SAR, and airborne laser scanning.

Prof. Wagner has been a member of the Science Advisory Groups for the Soil Moisture and Ocean Salinity Mission [European Space Agency (ESA)] and the Metop Advanced Scatterometer (European Organization for the Exploitation of Meteorological Satellites and ESA). He was the Committee Chair of the European Geosciences Union Hydrologic Sciences Sub-Division on Remote Sensing and Data Assimilation from 2005 to 2008. In support of his M.S. and Ph.D. studies, he received fellowships to carry research at the University of Bern, Bern, Switzerland, the Atmospheric Environment Service, Ottawa, Canada, the NASA Goddard Space Flight Center, Greenbelt, MD, the European Space Agency, Noordwijk, The Netherlands, and the Joint Research Centre of the European Commission. 